\title{
Impact of a physical activity intervention for weight loss: A qualitative analysis of participant perceptions and expectations
}

Jessica Anne Creasy

West Virginia University

Follow this and additional works at: https://researchrepository.wvu.edu/etd

\section{Recommended Citation}

Creasy, Jessica Anne, "Impact of a physical activity intervention for weight loss: A qualitative analysis of participant perceptions and expectations" (2008). Graduate Theses, Dissertations, and Problem Reports. 4364.

https://researchrepository.wvu.edu/etd/4364

This Thesis is protected by copyright and/or related rights. It has been brought to you by the The Research Repository @WVU with permission from the rights-holder(s). You are free to use this Thesis in any way that is permitted by the copyright and related rights legislation that applies to your use. For other uses you must obtain permission from the rights-holder(s) directly, unless additional rights are indicated by a Creative Commons license in the record and/ or on the work itself. This Thesis has been accepted for inclusion in WVU Graduate Theses, Dissertations, and Problem Reports collection by an authorized administrator of The Research Repository @ WVU. For more information, please contact researchrepository@mail.wvu.edu. 
Impact of a Physical Activity Intervention for Weight Loss: A Qualitative Analysis of Participant Perceptions and Expectations

\author{
Jessica Anne Creasy \\ Thesis submitted to the \\ College of Physical Activity and Sport Sciences \\ at West Virginia University \\ in partial fulfillment of the requirements for the degree of \\ Master of Science \\ in \\ Sport and Exercise Psychology
}

Samuel Zizzi, Ed.D., Chair

Edward Etzel , Ed.D.

Lori Sherlock, M.S.

Morgantown, WV

2008

Keywords: weight loss, physical activity, self-esteem, body image, qualitative 


\begin{abstract}
Impact of a Physical Activity Intervention for Weight Loss: A Qualitative Analysis of Participant Perceptions and Expectations

Jessica Anne Creasy
\end{abstract}

The purpose of this study was to investigate perceptions of self-esteem and body image and expectations for success among participants enrolled in a physical activity and nutritional intervention for weight loss. Qualitative research methods (individual interviews) were conducted to assess how participants felt about themselves, their bodies, and the intervention. In all, 10 participants were interviewed; five were in the initial week of the weight loss intervention (Phase I) and five had been enrolled in the intervention between 9-13 months (Phase II). Weight in pounds and body fat percentage were obtained for all participants at time of enrollment, and at the time of interview completion. Several themes were identified, including similar participant characteristics, key program characteristics, the primacy of physical self-esteem, and changes to self-esteem. The results suggest that similar participant characteristics, duration of treatment, and sequencing of physical activity and nutritional components be considered for design and application of weight loss interventions. In addition, the incorporation of a psychological component addressing self-esteem and self-acceptance in order to improve well-being and motivation may help participants adhere to behavioral changes in the long-term. 


\section{Acknowledgements}

Thank you to my committee, Dr. Sam Zizzi, Dr. Ed Etzel, and Lori Sherlock, M.S., for graciously providing your time and expertise.

An extra thanks to Dr. Zizzi for allowing me flexibility in this project. I have learned much; not only about conducting research, but about being open to experience, adaptation, and growth as well.

Thank you to Dr. Christiaan Abildso and Justine Vosloo, M.S. for your excellent "research karma," your time and effort in helping with data analysis, and your overall excellent mentoring.

A big thanks to Lorraine Levitsky, Parker Hall, Sarah Edwards, Noelle Dodge, and all the staff at the site facility. I couldn't have made it work without your generosity, kindness, and collaboration.

Finally, thank you to Justin. Not only do you challenge me to achieve and support me unconditionally; you even offer to falsify data for me. Your love is what got me through! 
Introduction .1

Methods .4

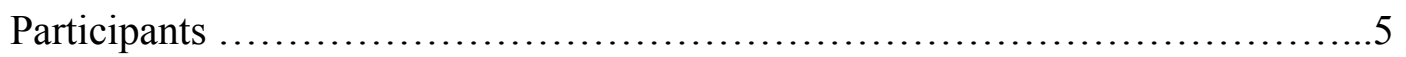

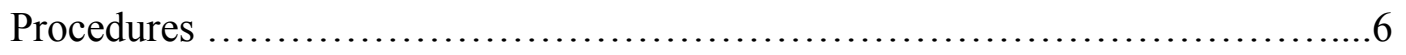

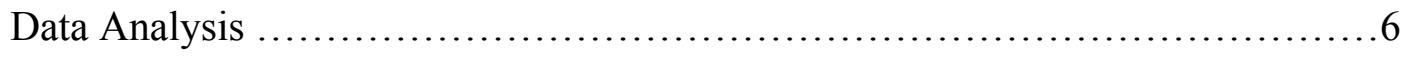

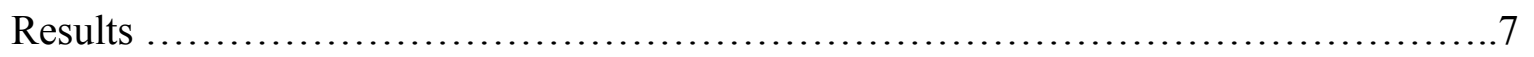

Physical Characteristics ..............................................

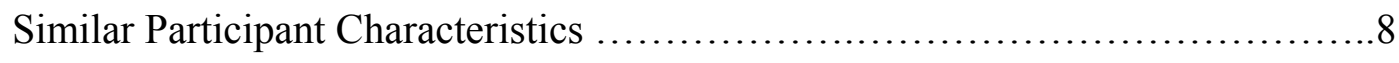

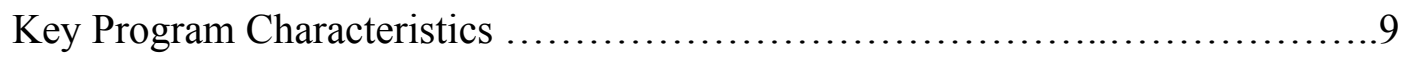

Primacy of Physical Self-Esteem ......................................11

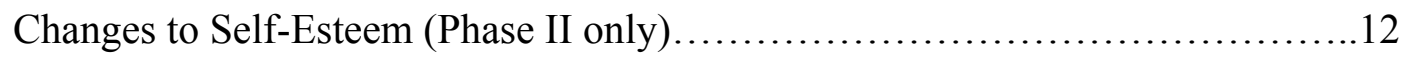

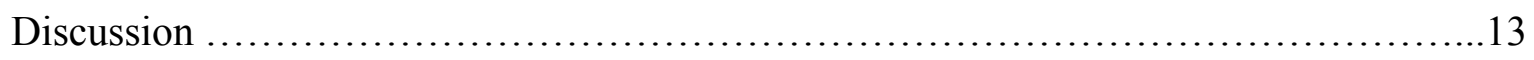

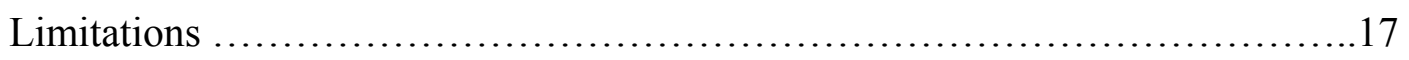

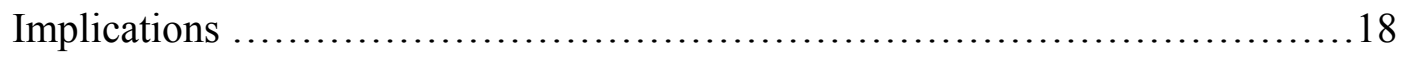

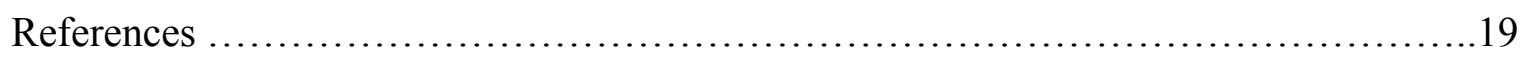

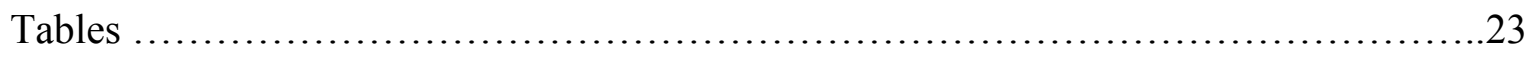

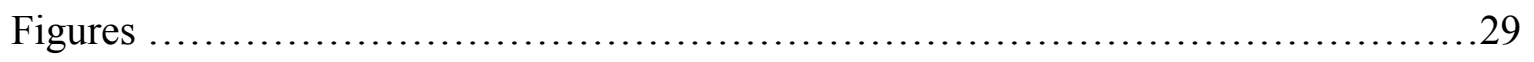

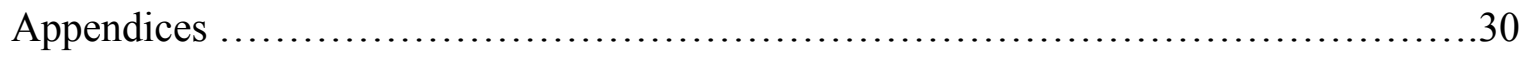

Appendix A: IRB Approval ............................................. 30

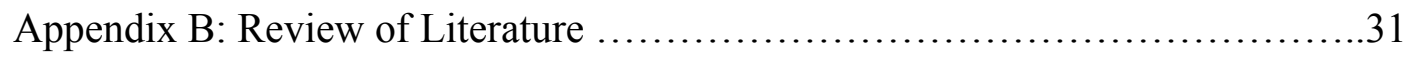




\section{List of Tables}

Page

Table 1. Participant Demographics

Table 2. Qualitative Interview Scripts

Table 3. Similar Participant Characteristics

Table 4. Key Program Characteristics

Table 5. Primacy of Self-Esteem 27

Table 6. Changes to Self-Esteem (Phase II only) 28 


\section{List of Figures}

Page

Figure 1. Sonstroem \& Morgan's (1989) Exercise and Self-Esteem Model. 


\section{Introduction}

Since the benefits of physical activity are myriad, it is surprising that approximately 55$70 \%$ of U.S. adults are sedentary. ${ }^{1}$ This high prevalence of inactive adults is especially disconcerting considering a lack of regular exercise increases one's risk for obesity and resultant health concerns like coronary heart disease and diabetes. ${ }^{2}$ Still, weight control issues abound and with them not only problems of physical health, but mental health as well. Adoption of a regular exercise program can serve not only to increase strength and decrease body fat, but can also provide participants with a greater sense of physical- and self-satisfaction. ${ }^{3-4}$ With a dangerous obesity epidemic in the United States and elsewhere, it is important for treatment programs to understand the effect of improved psychological constructs for increasing well-being and the likelihood of successful exercise adherence and weight loss maintenance.

Numerous studies have been undertaken that examine the positive effects of physical activity on self-esteem. For instance, a study by Palmer ${ }^{5}$ used an eight-week walking program to evaluate the effects of exercise on self-esteem in women, and found that subjects assigned to the walking group showed increased levels of self-esteem compared to women in the control (nonwalking) group. Others have distinguished between global self-esteem and more specific components such as physical self-esteem or academic self-esteem. Sonstroem and Morgan ${ }^{6}$ proposed a model of the interaction between exercise and self-esteem that is hierarchical and progresses from an individual's self-perceptions of confidence on specific physical activities up to one's general feeling of self-esteem (See Figure 1). The common argument for the model's use is that measuring the effects of physical activity on general or nonphysical concepts is ineffective, and instead the multidimensionality of self-esteem must be taken into account. ${ }^{7}$ 
Since self-esteem can be affected by one's level of physical activity, it would naturally follow that body image and satisfaction could be mediated as well. In fact, self-esteem and body image are intricately related, with those who exhibit high dissatisfaction with their bodies rating lower in self-esteem. ${ }^{8-9}$ Matz, Foster, Faith, and Wadden ${ }^{10}$ reported that self-esteem may in fact regulate body image dissatisfaction, and suggested that helping people separate feelings of worth from body shape and size may serve to enhance both measures.

So, while much attention has been paid to increases in self-esteem and body image through initiation of physical activity, there has been little focus on the role that change in weight has played in this modification. Only recently was a meta-analysis by Blaine, Rodman, and Newman ${ }^{11}$ conducted that examined 117 different weight loss treatments. Of these treatments, 89 were classified as "psychotherapy-based" and 28 were classified as "drug/surgery-based;" none of the treatment interventions was listed as primarily "physical activity-based," nor did the authors discuss the application of nutritional or exercise guidelines in either treatment category. The authors determined that predicted improvement in self-esteem occurred only with actual weight loss, and hypothesized that this may be due to increased internalized positive perceptions of social appraisals of one's body. It could be assumed that any differences in psychological well-being would vary by individual; some may have higher increases in self-esteem or body image satisfaction due to weight loss, while others can show similar changes with participation in exercise regardless of weight loss. However, the results of their seminal review show that further research must be done in order to determine the influence of either activity or weight loss on one's perceptions of self.

Qualitative research examining psychosocial changes with initiation of physical activity and weight loss has been infrequent. Crone, Smith, and Gough ${ }^{12}$ determined through qualitative 
methodology that the experience of exercise itself may be important for self-acceptance, irrespective of the amount of weight lost. In addition, the authors concluded that conditional themes of social support, social network, culture, and environment were also important for increasing contentment with one's present self. However, the study was comprised of subjects referred for general health reasons, and thus may not generalize to obese populations.

In another qualitative analysis, Sarlio-Lanteenkorva ${ }^{13}$ noted a tension described by women who had lost weight between who they were in the present, and their former obese selves. Despite commenting on improvements in self-esteem and health, the women still felt as though they were different from other people. It could be hypothesized that body image does not change as rapidly as self-esteem with weight loss, and thus these women still held negative views of their appearance despite an overall sense of improvement. Thus, while it is well documented that participants often experience increases in self-esteem and body image satisfaction after beginning a physical activity or weight loss intervention, ${ }^{4-5 ; 14-15}$ it is less clear what their perceptions are as to the mechanisms that are driving such changes. Further research is warranted to determine how participants in weight loss interventions perceive changes in the way they feel about their body and themselves. Gaining a clearer understanding of how exercise and weight loss each shape self-esteem may be of great benefit to the design and implementation of programs targeting physical activity and lifestyle weight management, as an improved sense of self may promote long-term adherence to behavior change.

In addition, it is important to ascertain what participants' expectations are from an intervention, and whether participants believe such expectations have been met at the cessation of a program. It was previously found that participants in exercise interventions who had overly optimistic or unrealistic expectations were more likely to be disappointed when goals were not 
met and drop out. ${ }^{16}$ In contrast, participants with modest expectations were more likely to meet or almost meet goals, thus building perceptions of success and maintaining greater adherence to exercise prescriptions. With the decreases in physical activity levels often seen after an intervention ends, ${ }^{17}$ it is not surprising that a large percentage of participants losing weight regain or exceed their pre-treatment weight within three to five years. ${ }^{18}$ In fact, from their metaanalysis, Blaine, Rodman, and Newman ${ }^{11}$ determined that weight loss treatments are not effective at promoting and sustaining significant weight loss, a conclusion that has been supported through previous qualitative research. ${ }^{19-20}$ Therefore, understanding what participants think about their experience in a weight loss intervention, as well as what was helpful for creating and maintaining behavioral and psychosocial change, may be very important in helping them maintain any positive changes made during the program.

\section{Methods}

Participants in this study $(N=10)$ were recruited from the Public Employee's Insurance Agency (PEIA) Weight Management Program (WMP) at an exercise and physical therapy facility in Morgantown, WV. The WMP is divided into three phases. Phase I is twelve weeks in length, and participants are required to exercise with an exercise physiologist for one hour, two days per week. In addition, participants are required to exercise an additional three days per week for one-hour sessions, and must complete an exercise log for any day they exercise outside of the fitness facility. Participants in Phase I also meet with a registered dietician at the initiation and cessation of the 12-week program, and are required to keep a food diary throughout the duration. Thus, all WMP participants are expected to engage in physical activity at least five days per week, and all logs are monitored by the site facility staff to ensure compliance. Weight, 
body fat percentage, and other measurements are taken once per month by facility staff. Participants must pay a $\$ 45$ copayment each month for the initial three months of Phase I.

At the completion of Phase I, eligible participants are given the option of entering Phase II. Phase II is comprised of the remaining nine months of a year, and participants pay approximately $\$ 14$ per month. While no longer required to meet with an exercise physiologist or submit weekly food diaries, participants are still expected to meet physical activity guidelines and be weighed and measured monthly. Phase III begins at the second year of program participation, and expectations are the same as those for Phase II. PEIA pays half of the participant's fitness facility monthly fee up to a total of no more than $\$ 50$ for one year in Phase III.

\section{Participants}

Eligible participants for the WMP must have a BMI of 30 or greater, or a BMI of 25 or greater and a related health condition such as diabetes or heart disease. Participants for this study included members from Phase I $(n=5)$, and members from Phase II $(n=5)$. Participants were recruited in person by the first author during initial meetings with the dietician, or by phone. Convenience sampling was utilized, as every new Phase I member was contacted about participation until five interviews were completed; only one member declined to participate, citing a lack of time. Members having completed at least Phase I were contacted based on length of time in the WMP; participants having been in the program the longest were contacted sequentially until five interviews were completed, and approximately ten members in Phase II were contacted in order to conduct five interviews. See Table 1 for participant demographics. 


\section{Procedures}

Participants were interviewed by the first author at a private location onsite at the exercise and physical therapy facility. Two semi-structured interview scripts were followed; one for participants in Phase I, and one for participants in Phase II. Interviews were recorded and transcribed verbatim, and all interviews lasted between approximately ten and thirty minutes. See Table 2 for interview scripts.

\section{Data Analysis}

A combination of grounded theory methodology ${ }^{21}$ and framework analysis ${ }^{22}$ was used in the analysis of interview data. All five key stages of framework analysis were employed, including familiarization with the data through listening to audio and reading the transcriptions; identifying a framework by making notes on common concepts and ideas; indexing data through comparison within and between subjects; charting by rearranging quotes and concepts under newly developed categories; and finally mapping and interpreting the data to create coherent and identifiable themes. During the familiarization and identification stages, transcripts were created for each interview question, and participant's answers listed under each question. These transcripts, as well as entire original transcripts per participant, were provided to two trained research assistants. Codes and coding instructions were developed and used by the researchers to group common interview data and achieve investigator triangulation. ${ }^{23}$ Concepts and categories were then determined based on the coding of participants' responses, leading to the creation of several higher-order themes for Phase I participants, Phase II participants, and all participants. 


\section{Results}

After analysis, several higher-order themes were apparent. These included: similar participant characteristics, key program characteristics, the primacy of physical self-esteem, and changes to self-esteem (for Phase II participants only). Several lower-order categories were determined for each theme, and will be discussed in the following sections. See Table 1 for detailed physical characteristics of participants. Verbatim quotes from participants regarding each theme can be found in Tables 3-6.

\section{Physical Characteristics}

All study participants in Phase I were female, and their average age was 52. The average starting weight for Phase I participants was 195.36 pounds, with a range of 156.0 to 232.2 pounds. The average starting body fat percentage was $43.28 \%$ for Phase I participants, and the range was $38.9 \%$ to $47.7 \%$. Phase II participants were comprised of two males and three females, and their average age was also 52. The average starting weight of Phase II participants was 231.48 pounds, and the range was 159.4 to 344.0 pounds. The average starting body fat percentage was $41.04 \%$ for Phase II participants, and the range was $32.0 \%$ to $44.9 \%$. For all participants, weight at initiation of Phase I ranged between 156.0 and 344.0 pounds, and the average initial weight was 213.42 pounds. Starting body fat percentage for all participants ranged between $32.0 \%$ and $44.9 \%$, and the average body fat percentage was $42.16 \%$.

Among the five participants in Phase II, the average weight loss was 29.56 pounds. Weight changes ranged from a gain of ten pounds for participant \#6 to a loss of 56.8 pounds for participant \#8. Participant \#6 reported a weight loss of about 20 pounds during Phase I; however, he gained this weight back plus more over the duration of Phase II. Still, participant \#6 reported being confident that he could lose this weight again, and was pleased with a perceived gain in 
muscle mass, which may partially account for his $.9 \%$ decrease in body fat despite the weight gain. The average decrease in body fat percentage for participants in Phase II was 5.16\%, and decreases ranged from $.9 \%$ to $7.6 \%$.

\section{Participant Characteristics}

Several common characteristics were observed for both Phase I and Phase II participants. $80 \%$ described a recent health scare or a family history of negative health issues as being a primary reason for their joining the WMP. Another characteristic shared by both Phase I and Phase II participants was previous experience with regular physical activity and weight loss. All participants discussed having tried various strategies to lose weight before having joined the WMP, including diet and exercise. Many participants described having previously been regularly active, and about $70 \%$ had successfully lost weight in the past. Participants in Phase I all identified a decline in physical activity once they'd reached their thirties and forties, though all described having been regularly active up until that point. It is important to note that the activities done previously by all members were primarily non-gym based, such as walking or biking outdoors. In addition, four out of five Phase I members reported having previously been their ideal body size at a time when they were regularly physically active.

Despite previous experience with weight loss success, nine of ten participants expressed low self-efficacy for current weight loss. In Phase II members, this was demonstrated through the belief that weight loss would not have been achieved without joining the WMP. For example, when asked if she thought she could have reached her weight loss goals without joining the program, participant \#7 replied "Probably not. I wouldn't have been motivated to do it on my own." For Phase I members, low self-efficacy was expressed through both discussion of recent 
failures at attempted weight loss, as well as a current fear of failure without participation in the program.

A final common characteristic seen in both Phase I and Phase II participants was an emphasis on health-related goals and outcomes. For Phase I participants, becoming active and reaching outcomes pertaining to health were stressed over weight loss goals. Phase II participants often described weight loss goals as having been more important initially; however four out of five Phase II participants had not yet met their weight loss goals at the time of interview. Therefore, health-related outcomes were highlighted, as articulated by participant \#10: "Weight loss is slow, but the benefits are good. My knees don't hurt now. I'm less stressed, have more energy, sleep really good."

\section{Key Program Characteristics}

Key program characteristics were identified by all participants, and included components of the program that were viewed as being beneficial. Phase I participants all reported a desire to stay in the WMP for at least a year, with the hope that they would reach their goals by the end of the 12-month time period. When asked if she foresaw herself staying the program through Phase I, participant \#4 said “Oh absolutely. Yeah. Or whatever it takes.” In addition, Phase II participants, many of whom had completed almost a year's time in the WMP, expressed not only an intention to maintain the level of physical activity they had achieved in the program, but a desire to continue on into Phase III. Therefore the length of the intervention was both appreciated by participants, in that all wished to complete at least two of the three phases, and two participants in Phase II articulated a desire to see the program extended even further.

Participants in both Phases I and II expressed the need for accountability in a weight loss program. Phase I members saw accountability as something that might promote success. Phase II 
members discussed aspects of the WMP that held them accountable, such as food logs, and how this led to their perceived success. For example, participant \#10 said "They have their expectations of how often you have to come; that helps. That does help keep me here."

Participants in Phase II also frequently cited the combination of diet and exercise as being beneficial to their success in the program. Three described the exercise component as being difficult at first, but all found it easier to maintain than the nutritional component. Participant \#9 noted that "...the exercise has been challenging," however she also described her progress so far in the program as "I'm addicted to exercise." Thus, while the initial adoption of an exercise routine may be difficult, participants in Phase II often reported an enjoyment of and determination to stick with their current levels of physical activity. Phase I participants also frequently described the exercise component as being beneficial for success; physical activity may have been seen as more beneficial because participants had some self-efficacy for exercise having been regularly active in the past. The nutritional component was not specifically discussed by Phase I participants in relation to success. Despite citing the combination of proper diet and physical activity for success, Phase II participants repeatedly described nutrition as the most challenging aspect of the WMP, and expressed a desire for further help in this area.

Finally, Phase II participants commonly discussed the importance of making a lifestyle change and prioritizing that change for success. Participant \#8 said “...to lose weight, and to lose it effectively you have to make a change in your lifestyle," and participant \#10 stated “...it's kind of gone up on my list of priorities." Thus, participants recognized the importance of incorporating physical activity and dietary changes into their daily lives in order to maintain weight loss. 


\section{Primacy of Physical Self-Esteem}

For the participants of the WMP, physical self-esteem seemed to be of the highest importance. Further, there was a kind of enmeshment of body image and self-esteem that was often expressed as participant \#4 put it: "look good, feel better." The immediacy of weight and weight loss goals was also an indication of the importance of physical self-esteem. For example, when asked to describe her overall feelings about herself, participant \#3 responded 'I've never been this heavy before." Participant \#1 was asked how she thought her feelings about her body might change after previously answering how her feelings about herself overall might change; her response was "Isn't that what you just said?" It could be that participants were primed to answer with physical terms first, as the interview took place in relation to membership in a weight loss program. However, other factors reflected the importance of physical self-esteem.

For example, participants in Phase I reported having higher self-esteem when previously physically active and at their ideal body weights. In addition, they uniformly predicted that selfesteem would increase with weight loss. This theme shows that participants believed that how they felt about themselves physically dramatically affected their overall sense of self-worth.

Another common theme among both Phase I and Phase II participants when discussing their feelings about themselves was the frequent mention of clothing. One's dress is an immediate and fairly objective measure of weight, and most participants described themselves in terms of how their clothes fit. In addition, participants occasionally described the effect of seeing pictures of themselves when discussing self-esteem; pictures may represent another more concrete measure of one's appearance.

Participants in Phase I frequently expressed shame in regards to their self-image, and these feelings were often brought up in relation to how participants felt not only about their 
bodies, but about themselves overall as well. Three participants mentioned limiting their choice of clothing because of a dislike of the way they looked, which could be an indication of social physique anxiety. At times, participants' disgust with their self-image was stated more explicitly. When asked to describe her overall feelings about her body participant \#1 simply said "Eeew." Other participants related stories about feeling they were treated differently due to their weight, or being subjected to criticism from others. Finally, two participants described limiting social events because of their dislike of their bodies or themselves. For instance, participant \#2 stated "I haven't attended some things like that, avoided having pictures taken..."

\section{Changes to Self-Esteem (Phase II only)}

Though participants in Phase I often expressed a deep dislike of their appearance and selves, Phase II participants all described a clear improvement in self-esteem. Participants used words such as "good," "great," and "better" when discussing their feelings about themselves and their bodies. In addition, many participants verbalized a desire to maintain the activity levels and weight loss they'd achieved in order to preserve these new enhanced feelings. For example, when asked if her feelings about herself would have been different if she had not met her weight loss goals, participant \#10 replied "Maybe a little. But not nearly as much as it was before I exercised." So it's possible that feeling better may help participants adhere to a physical activity program and maintain weight lost during an intervention. Another common way that Phase II participants communicated increased self-esteem was through a decrease in self-criticism. Participant \#10 noticed that she was more "patient" with herself, while participant \#7 predicted she would have had more “...'why are you failing again' kind of thought” had she not met her weight loss goals. Thus, part of the reason Phase II members may have felt better about themselves was decreased negative thinking related to their weight and appearance. 


\section{Discussion}

While Sonstroem and Morgan ${ }^{6}$ hypothesized that sub-domain levels of esteem such as physical competence and physical acceptance have a small effect on global self-esteem, it appears that at least to obese members of a weight loss intervention, physical self-esteem is paramount in determining one's overall sense of worth. It is not surprising that physical appearance should have a large effect on one's self-esteem, given the current standards of thinness and beauty portrayed in media. Women, and increasingly men, ${ }^{24}$ face great pressure to meet ideals for shape and size that are unrealistic for most individuals. Low self-esteem was pervasive among individuals beginning the Weight Management Program (WMP); in fact, two out of ten participants in this sample exhibited a fairly stable and pervasive negative self-image. However, the majority of those having completed almost a year showed major improvements in their feelings about themselves and their bodies, and used these new feelings as motivation to continue. As participant \#10 said in response to her plans for remaining physically active: "I want to keep feeling like this." Therefore, the incorporation of a cognitive-behavioral component focusing on self-esteem and self-acceptance may enhance self-efficacy for behavior change and promote greater long-term adherence.

While weight management programs featuring interventions for self-esteem have not always been associated with improved outcomes, ${ }^{25}$ some may have focused on ineffective means of enhancing participants' feelings. For instance, Friedman et al. ${ }^{26}$ recommended teaching participants to disassociate weight with their sense of self-worth. However, participants' body image and physical self-esteem may be so integral to global self-worth that to separate them is impossible. Instead, programs targeting self-esteem could teach participants to become aware of increased self-efficacy, and reduce social physique anxiety by promoting strategies to help 
participants be more accepting of their current body size rather than a previous size or ideal. Participants in the WMP used successes with health goals and progress towards weight loss goals to build self-efficacy for change and decrease self-criticism. Thus, a cognitive-behavioral component that emphasizes self-acceptance, while also reinforcing the process of weight loss (e.g., meeting physical activity and dietary guidelines), may promote increased self-esteem and adherence. This is supported by Nir and Neumann's ${ }^{27}$ finding that greater self-esteem predicted better weight loss maintenance after intervention cessation.

Nir and Neumann ${ }^{27}$ also advised that participants with lower initial self-esteem may require interventions of longer duration for improved weight loss outcomes. This is consistent with the findings that WMP participants typically desired to remain in the program for at least a year. Because the participants in Phase I all displayed feelings of low self-esteem, it may be prudent to increase the duration while maintaining accountability of Phase I to one year, rather than the current twelve weeks. Participants in Phase I all expressed low self-efficacy for change on their own, and twelve weeks may not be ample time to build the skills necessary for participants to maintain changes in physical activity and diet on their own. Considering that participants in Phase II, who had been in the program for at least nine months, also planned to continue in the program for as long as possible, lengthening the intervention duration may lead to better maintenance of behavior change in the long-run. Many Phase II participants identified that changes to their diet and exercise routines were lifestyle modifications. This is an important distinction, as participants were thus not looking at change as being only for the duration of the intervention and long-term adherence may be more likely. According to Prochaska and Velicer, ${ }^{28}$ behavior change requires at least six months to become routine. Therefore, extending the amount of time that participants are held accountable and required to meet program guidelines, and 
emphasizing these behaviors as a new lifestyle may help participants to form and adapt to longterm habits.

In addition to accentuating behavioral change for life, weight loss interventions might also consider stressing the importance of adopting an active identity. This idea has been supported through both qualitative and quantitative research into maintenance of exercise behaviors and exercise self-schema. ${ }^{29-31}$ Several participants in Phase I discussed no longer feeling like themselves after weight gain, and one explicitly stated "I want to be a new me." By endorsing physical activity as a way of life, individuals may begin to look at themselves not as someone who is overweight, but as someone who is taking care of his health. Phase II participants often emphasized meeting or making progress towards health goals, so highlighting these successes and promoting exercise and proper nutrition as an integral part of who the individual is, rather than the means to an end, could improve weight loss outcomes and maintenance.

Participant responses also suggest that the sequencing of changes in exercise and nutrition be examined. Most participants in the WMP had been regularly physically active at some point in their lives; however, most of them reported completing activities that were nongym based such as walking and cycling. Participants in Phase I commented on the benefit of exercise for their weight loss goals, but many had low self-efficacy for a gym-based program. This theme was reflected in several participants' responses, such as when participant \#2 said “... if you don't normally do a gym, if you didn't start off like maybe in high school going to a gym or doing an activity like that, it's a very difficult activity to just join,” and participant \#4 stated "...I was doing a variety of things, but not gym-related stuff, it was more outdoor stuff, more athletic things. The gym never really was my forte or my interest." Therefore, weight loss 
interventions might initially incorporate more activities that participants are already comfortable with, such as walking outdoors, in order to decrease the potential for negative outcomes such as muscle soreness and frustration. Phase II participants cited the importance of gym-based fitness programs, but did comment that they were difficult at first. Thus, gym-based activities such as strength training might slowly be added with increasing self-efficacy for exercise in order to maximize participants' perceptions of success.

The combination of exercise and proper nutrition was very important to participants in Phase II. However, several participants noted that the nutritional component was much more difficult than the adoption of physical activity. Therefore, it may be beneficial to delay the incorporation of nutritional change until after physical activity has become consistent. Many participants cited the ease of maintaining physical activity behaviors once they became routine, but noted that adhering to proper nutritional guidelines was a struggle. Prochaska and Sallis ${ }^{32}$ have suggested further research on single behavior interventions in order to better understand the motivational and cognitive processes associated with change. It may be that participants are only able to focus on one behavior change at a time, and if the nutritional component is reserved until exercise has become part of one's lifestyle, then more energy may be available for proper dietary choices. Because of its perceived difficulty, the intensity of support provided by staff during the nutritional component may also need to be strengthened, such as through regularly scheduled meetings with a dietician for a significant period of time.

Finally, as important as weight loss interventions are for an increasingly obese population, programs focused on primary prevention should not be overlooked. Physical activity interventions to prevent sedentary behaviors could be beneficial for decreasing risk of disease as well as lowering medical and insurance costs. Most of the participants in Phase I discussed 
decreases in physical activity levels starting in their early thirties or forties. Therefore, interventions targeting women in these age brackets might help reduce the risk of obesity later in life by promoting long-term maintenance of regular activity. As well, most participants in the WMP cited a recent health scare or family history when discussing their reasons for joining the program. Rather than waiting until risks to health are severe, programs should be offered to individuals with a family history of common diseases such as type-two diabetes or heart disease in order to prevent onset and the sedentarism that is often comorbid. One effective means for providing physical activity interventions is offering programs in the work setting. As most adults spend a significant amount of time in the workplace, worksite interventions not only have the potential to reach large numbers of people, but are often more convenient and affordable for individuals as well. ${ }^{33}$

There were several limitations to the current study. First, generalizability is limited due to the specific population that was interviewed. Participants in this study had all had previous experience with physical activity, which may have affected their responses and perceptions about themselves and the program. As well, the sample was comprised mainly of women, so translation across genders is questionable. Men's body image is often centered more on gaining muscle than decreasing fat, ${ }^{9}$ and this was reflected in some of the male participants' comments. Thus, suggestions and implications for programmatic changes may be limited to female participation. Another limitation may have been interviewer bias, as the author has a personal history of weight loss and self-esteem change; thus, some transference and countertransference may have taken place during the interviews. There may have been some bias in response for Phase II participants as well, as it is possible the participants who agreed to be interviewed had a more positive experience in the WMP and thus may have perceived greater changes in self- 
esteem. Finally, demand characteristics and social desirability may have been a factor, as participants could have answered questions in order to please the interviewer.

Future research is necessary to determine how much self-esteem impacts weight loss behaviors and maintenance. Components targeting self-acceptance and promotion of an active identity must be studied further in order to ascertain their effectiveness on weight loss outcomes. In addition, additional study must be done on the sequencing of intervention components. It is possible that staggering the initiation of physical activity and nutritional changes may allow participants to build self-efficacy for exercise and reserve energies for the perceived difficulty of dietary modification. Finally, further study incorporating qualitative research methods should be completed. Qualitative analysis provides a richer context in which to understand interventions, as detailed data comes directly from participants. Despite the objective information that quantitative research provides, there is no one better to explain what works for weight loss maintenance or self-esteem enhancement than those who have experienced these often life-changing processes. 


\section{References}

1. Macera C, Ham S, Yore M, et al. Prevalence of physical activity in the United States: Behavioral Risk Factor Surveillance System, 2001. Prev Chronic Dis 2005; 2(2): A17A17.

2. Booth FW, Chakravarthy MV. Cost and consequences of sedentary living: new battleground for an old enemy. Pres Counc on Phys Fit and Sports Res Dig 2002; March: 1-8.

3. Sonstroem R, Harlow L, Gemma L, Osborne S. Test of structural relationships within a proposed exercise and self-esteem model. J Pers Assess 1991; 56(2): 348.

4. Tiggemann M, Williamson S. The effect of exercise on body satisfaction and self-esteem as a function of gender and age. Sex Roles 2000; 43(1/2): 119-127.

5. Palmer L. Effects of a walking program on attributional style, depression, and self-esteem in women. Percept Mot Skills 1995; 81(3 Pt 1): 891-898.

6. Sonstroem R, Morgan W. Exercise and self-esteem: rationale and model. Med Sci Sports Exerc 1989; 21(3): 329-337.

7. Marsh H, Peart N. Competitive and cooperative physical fitness training programs for girls: effects on physical fitness and multidimensional self-concepts. J Sport Exerc Psychol 1988; 10(4): 390-407.

8. Bezner J, Adams T, Steinhardt M. Relationship of body dissatisfaction to physical health and wellness. Am J Health Behav 1997; 21(2): 147.

9. Furnham A, Badmin N, Sneade I. Body image dissatisfaction: gender differences in eating attitudes, self-esteem, and reasons for exercise. J Psychol 2002; 136(6): 581. 
10. Matz P, Foster G, Faith M, Wadden T. Correlates of body image dissatisfaction among overweight women seeking weight loss. J Consult Clin Psychol 2002; 70(4): 1040-1044.

11. Blaine B, Rodman J, Newman J. Weight loss treatment and psychological well-being. $J$ Health Psychol 2007; 12(1): 66-82.

12. Crone D, Smith A, Gough B. 'I feel totally at one, totally alive and totally happy': a psycho-social explanation of the physical activity and mental health relationship. Health Educ Res 2005; 20(5): 600-611.

13. Sarlio-Lanteenkorva S. 'The battle is not over after weight loss': stories of successful weight loss maintenance. Health N Hav 2000; 4(1): 73.

14. Depcik E, Williams L. Weight training and body satisfaction of body-image-disturbed college women. J App Sport Psychol 2004; 16(3): 287-299.

15. Nauta H, Hospers H, Jansen A. One-year follow-up effects of two obesity treatments on psychological well-being and weight. Br J Health Psychol 2001; 6(3): 271.

16. Jones F, Harris P, Waller H, Coggins A. Adherence to an exercise prescription scheme: The role of expectations, self-efficacy, stage of change and psychological well-being. $\mathrm{Br}$ J Health Psychol. 2005; 10(3): 359-378.

17. Marcus B, Williams D, Dubbert P, et al. Physical activity intervention studies: what we know and what we need to know: a scientific statement from the American Heart Association Council on Nutrition, Physical Activity, and Metabolism (Subcommittee on Physical Activity); Council on Cardiovascular Disease in the Young; and the Interdisciplinary Working Group on Quality of Care and Outcomes Research. Circulation 2006; 114(24): 2739-2752. 
18. Byrne S, Cooper Z, Fairburn C. Weight maintenance and relapse in obesity: a qualitative study. Int J Obes Relat Metab Disord 2003; 27(8): 955.

19. Cogan J, Rothblum E. Outcomes of weight-loss programs. Genet Soc Gen Psychol Monogr November 1992; 118(4): 385-415.

20. Rothblum E. Contradictions and confounds in coverage of obesity: psychology journals, textbooks, and the media. J Soc Issues June 1999; 55(2): 355-369.

21. Strauss AL, Corbin JM. Basics of Qualitative Research, Thousand Oaks, CA: Sage Publications; 1998.

22. Ritchie J, Spencer L. Qualitative analysis for applied social research. In: Bryman A, Burgess RG eds. Analyzing Qualitative Data. New York: Routledge; 1994: 172-194.

23. Denzin, NK. Sociological Methods: A Sourcebook. New York: McGraw-Hill; 1978.

24. Frith H, Gleeson K. Clothing and embodiment: men managing body image and appearance. Psychol Men Mascul January 2004; 5(1): 40-48.

25. Ramirez E, Rose J. A comparison of weight control and weight control plus body image therapy for obese men and women. J Consult Clin Psychol June 2001; 69(3): 440-446.

26. Friedman K, Reichmann S, Costanzo P, Musante G. Body image partially mediates the relationship between obesity and psychological distress. Obes Res January 2002; 10(1): $33-41$.

27. Nir Z, Neumann L. Relationship among self-esteem, internal-external locus of control, and weight change after participation in a weight reduction program. J Clin Psychol July 1995; 51(4): 482-490.

28. Prochaska, JO, Velicer, WF. (1997). The transtheoretical model of health behavior change. Am J Health Promot 1995; 12: 38-48. 
29. Haase A, Kinnafick F. What factors drive regular exercise behavior?: exploring the concept and maintenance of habitual exercise. J Sport Exerc Psychol July 02, 2007; 29: S165-S165.

30. Keraney, M, O'Sullivan, J. Identity shifts as turning points in health behavior change. West J Nurs Res March 2003; 25(2): 134-152.

31. Cardinal B, Cardinal M. Changes in exercise behavior and exercise identity associated with a 14-week aerobic exercise class. J Sport Behav December 1997; 20(4): 377-386.

32. Prochaska J, Sallis J. A randomized controlled trial of single versus multiple health behavior change: Promoting physical activity and nutrition among adolescents. Health Psychol May 2004; 23(3): 314-318.

33. Proper KI, Koning M, van der Beek AJ, Hildebrandt VH, Bosscher RJ, van Mechelen W. The effectiveness of worksite physical activity programs on physical activity, physical fitness, and health. Clin J Sport Med. 2003; 13(2): 106-117. 
Table 1

\begin{tabular}{|c|c|c|c|c|c|c|c|}
\hline \multicolumn{6}{|c|}{ Participant Demographics/Physical Characteristics } & \multicolumn{2}{|c|}{ (for Phase II only) } \\
\hline & \multirow[t]{2}{*}{ Gender } & \multirow[t]{2}{*}{ Age } & \multirow[t]{2}{*}{ Start Date } & \multicolumn{2}{|c|}{$\begin{array}{c}\text { Weight \%BodyFat } \\
\text { at start }\end{array}$} & $\begin{array}{r}\text { Weight } \\
\text { at }\end{array}$ & $\begin{array}{l}\text { \%BodyFat } \\
\text { terview }\end{array}$ \\
\hline \multicolumn{5}{|l|}{ PHASE I } & & & \\
\hline Participant \#1 & $\mathrm{F}$ & 57 & $6 / 08$ & 232.2 & 46.1 & & \\
\hline Participant \#2 & $\mathrm{F}$ & 38 & $6 / 08$ & 173.6 & 39.4 & & \\
\hline Participant \#3 & $\mathrm{F}$ & 56 & $6 / 08$ & 204.4 & 44.3 & & \\
\hline Participant \#4 & $\mathrm{F}$ & 59 & $6 / 08$ & 210.6 & 47.7 & & \\
\hline Participant $\# 5$ & $\mathrm{~F}$ & 51 & $6 / 08$ & 156.0 & 38.9 & & \\
\hline \multicolumn{8}{|l|}{ PHASE II } \\
\hline Participant \#6 & $\mathrm{M}$ & 53 & $8 / 07$ & 214.0 & 32.0 & 224.0 & 31.1 \\
\hline Participant \#7 & $\mathrm{F}$ & 49 & $6 / 07$ & 251.0 & 44.0 & 203.2 & 36.4 \\
\hline Participant \#8 & M & 45 & $7 / 07$ & 344.0 & 41.8 & 287.2 & 35.8 \\
\hline Participant \#9 & $\mathrm{F}$ & 56 & $6 / 07$ & 159.4 & 42.5 & 133.0 & 36.8 \\
\hline Participant \#10 & $\mathrm{F}$ & 60 & $10 / 07$ & 189.0 & 44.9 & 172.2 & 41.3 \\
\hline
\end{tabular}


Table 2

\section{Qualitative Interview Scripts}

Phase I

1. Why did you join the Weight Management Program (WMP) at this time?

2. What are your goals for the time you are in the WMP?

a. Do you have specific weight loss goals? 3. What is more important to you: meeting your weight loss goals, or becoming an active person? 4. How would you describe your overall feelings about yourself?

a. Why do you think you feel this way?

b. Have you always felt this way?

5. How would you describe your overall feelings about your body?

a. Why do you think you feel this way?

b. Have you always felt this way?

6. How do you think your feelings about yourself will change if you meet your weight loss goals?

a. What about your feelings about your body?

7. How do you think your feelings about yourself Will change if you complete the WMP but do not meet your weight loss goals?

8. Has there ever been a time when you were regularly physically active?

a. When (most recently)? What were you doing and for how long?

b. Were your feelings about yourself different? How?

c. Were your feelings about your body different? How?

9. Has there ever been a time when you were your ideal body size?

a. Were you regularly physically active at this time?

b. How did you feel about yourself then as compared to now?

10. What aspect of the WMP do you think will best help you reach your goals (physical activity, nutrition, support, etc.) and why?

11. If you were not enrolled in the WMP, do you think you would still be able to reach your goals?

a. Weight loss goals?

12. How do you think you will do in this program over the next three months? Six months? Year?

\section{Phase II}

1. Overall, how satisfied are you with your participation in the Weight Management Program (WMP)?

2. Have you met or exceeded your weight loss goals?

3. What part of the WMP did you like best (physical activity, nutrition, support, etc.)?

4. How did this component help you be successful?

5. What component did you like least? Why was it less helpful?

6. Why do you think you were able to meet your goals/be successful?

7. Have you noticed any changes in how you feel about yourself overall?

a. Why have your feelings changed/what do you think led to these changes?

8. Have you noticed any changed in how you feel about your body?

a. Why have your feelings changed/what do you think led to these changes?

9. If you had not met your weight loss goals, do you think your feelings about yourself would be different? How so?

10. If you had not met your weight loss goals, do you think your feelings about your body would be different? How so?

11. How important is maintaining the level of physical activity you've done in the WMP to you?

12. How important is maintaining the weight loss you've achieved in the WMP to you? 13. Is there anything that you think could have helped you be more successful in the WMP? 14. Do you think you could have reached your weight loss goals without joining the WMP? 


\section{Table 3}

\section{Similar Participant Characteristics}

Recent Health Scare/Family History

\section{Experience with Physical Activity and Weight} Loss

\section{Low Self-Efficacy for Weight Loss}

\section{Emphasis on Health-Related Goals and Outcomes}

\section{Verbatim Quotes}

“...there's diabetes in my family and I was high normal, and I was concerned, so I got into the program..."

"When I started this program I think I was 48 , so I was the same age that he was. And heart disease runs in my family, and so I mean, I was determined that I was going to get healthier because I wasn't ready to die yet."

"Because my father had his first heart attack at 48 and died at 50. So I just want to become more physically fit so that doesn't happen to me."

"And with the family history of grandfather, father having diabetes, that was what, in the back of my mind, was my fear."

"My blood pressure the last couple times I've been at the doc had elevated just a little bit, you know, just kind of scares me. Plus, my aunt and my mom have type two diabetes, arrhythmic hearts, lots of health problems because they've been overweight all their lives."

"I walked all the time, and now just nothing, so this gonna be a shock to my body."

“...I played softball for 20 years, and I did some kind of physical activity most of my life."

“...well you know, I've been successful in the past losing a little bit of weight here and there..."

“...but last year I lost 10 pounds before joining (facility)..."

"I'm a Weight Watchers lifetime member. So they taught me how to eat many years ago. But then I just got away from it."

"I lost a lot of weight several years ago, but over the course gained it back and I just couldn't get the willpower to do it by myself again."

"Because I've tried, and I failed."

"If I was alone it probably, I can't get my mindset to do it."

"...if I were to have tried this on my own, I would not have been successful."

"No, couldn't have done it."

"Because I want to do it. I want better health."

"...so I have this family history that's very strong, so I want to get as healthy as I can."

"...be able to play with my grandkids and to get off some of the medication that I'm currently on."

“...physical ailments and not feeling good, has totally changed. Um, there were just things I couldn't do, because of my knees. And now they've planned exercises that are not weight bearing and I can still exercise..." "I want to be healthy, that's the main thing. Both of my parents died of heart disease, and I need to be healthy." 
Table 4

Key Program Characteristics

Length of Program

\section{Accountability}

Combination of Diet and Exercise

Exercise as Beneficial

Nutrition as Challenging

Lifestyle Change and Priority
"I hope at the end of the year that I am almost where I want to be. But I don't even know if you can even do it again, or just continue with the program here."

"I'm gonna stay in as long as my health permits me."

"Well you know when they added Phase III, I was very excited." "I'm hoping to stay in the program, but if you know, after a year and all the program ends or whatever, I'll buy a membership and stay in..."

"First it was what, gonna be three months I think. No way. Three months is just gonna initiate. And then they added the other (Phase II), which was smart, and then they added this second year. I'm hoping they keep doing it."

"I think counting calories and keeping track a little bit more specifically..."

"I don't think I'd be nearly as disciplined."

"I'm the type person, I need almost like the drill sergeant in front of me..."

"...jus the accountability piece made a big difference."

"I have to know that I have to be somewhere and I have to do something, and if I had to do it on my own I would just say 'oh I need to do this or I need to do that, I don't have time to do that.",

"Because I combined the exercise, weight training which I've never done, and the nutrition aspect of it."

"Actually, it's a combination of everything, the exercise and the nutrition..."

"The exercise part of it works really well."

"I think the working out, that'll help."

“...the exercise part. Because I don't do any exercise."

"...I just was not adhering to what her guidelines were and all. I just wasn't writing things down."

"The eating is more challenging, the choices of food everyday that you have to decide upon. The eating is more challenging, because once you know how to, once they show you how to do these exercises, then you can do them."

"I really wish they would keep up the intensity level that they did for the first three months. Where you're forced to track what you're eating every day."

"It will be a lifetime. It was a change. And that's the whole thing about it, it's a lifestyle change."

"...trying to be healthy, I guess that is the priority, and just being healthy, the weight came off."

"...it's become like a part of my life now," 
Table 5

\begin{tabular}{l}
\hline Primacy of Physical Self-Esteem \\
\hline $\begin{array}{l}\text { Enmeshement of Body Image } \\
\text { and Self-Esteem }\end{array}$ \\
Self-Esteem and Ideal Body Size \\
Expectation of Self-Esteem with \\
Weight Loss
\end{tabular}

Clothes

Pictures

\section{Shame of Self-Image \\ Limiting Clothing Choices}

\section{Feelings of Dislike/Disgust}

Perceived Prejudice

Limiting Social Activities

\section{Verbatim Quotes}

"I just felt that I looked better, I felt better."

"...I need to feel better, I don't like the way I look."

"I don’t like how I look or feel."

"I felt really good about myself."

"I felt a lot better about myself. Definitely."

"I think I'll be on cloud nine."

"I think that I'll feel a lot better about who I am..."

"I think I'll be more self-assured, maybe be able to dress nicer."

"I think that I'll feel a lot better about who I am and, because I can wear and look decent professionally."

"It's nice to go shopping, it's nice to pull things out of your closet and they're getting too, they're all too big."

"right now at this moment, looking at pictures of myself, I feel like I don't look like myself."

"Pictures, it's just amazing."

"I don't ever wear shorts. I don't ever wanna be in a bathing suit."

"I don't get in a bathing suit, I don't wear short sleeves. Just not real proud of it right now."

"...wore bikinis all the time, and short shorts and halter tops. But now that I've gained all this weight I don't want to do that."

"Geez, it's easier to buy clothes, you know, I can buy clothes in a 'regular size' store now."

"I don't like the way I look."

"Eeew. Is that enough? Eeew."

"Oh I think its horrible. I think I look horrible." "I still have people react differently to me and I can see it."

“...I have a goal at work too that I would like to do and, I know this sounds awful, but I think it would help me achieve that goal."

"I know, its like society, I know."

"...or not going to some things..."

"I don't go out socially hardly at all anymore." 
Qualitative Analysis of Weight Loss 28

Table 6

Changes to Self-Esteem (Phase II only)

Verbatim Quotes

Increased Self-Esteem

"I feel better about myself. I feel confident."

"I feel great about myself."

"I feel good."

"I want to keep feeling like this."

“...I wouldn't want to backslide, I mean I

feel good and I'd like to maintain this activity."

Decreased Self-Criticism

"I'm more patient with myself..."

“...it's a great feeling. Because I was down on myself all the time."

"I'm less critical."

“...there'd be a lot more self-hatred going on." 


\section{General}

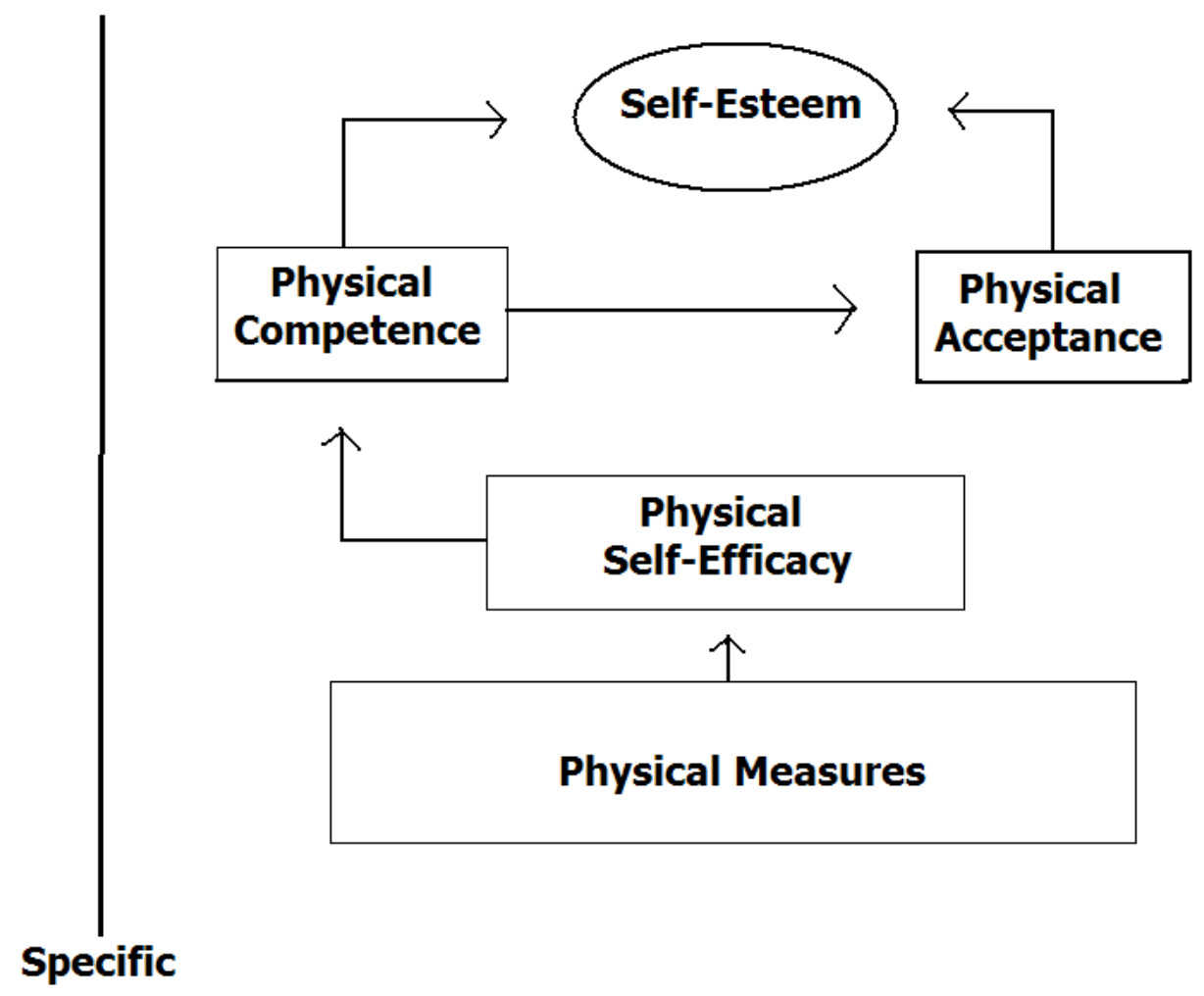

Figure 1. Sonstroem \& Morgan's (1989) Exercise and Self-Esteem Model. 


\section{Appendix A}

\section{IRB Approval}

Protocol approved by the Institutional Review Board for the Protection of Human Subjects at West Virginia University on 02/21/2008

Tracking \#: H-20658

PI: Zizzi, Samuel

Title: The Effects of a Physical Activity Intervention for Weight Loss on Self-Esteem and Body Image

Approval Date: 02/21/2008

Expiration Date: 02/20/2009

Amendment approved on 06/20/2008.

Tracking \#: AMEND-1104 (H-20658)

PI: Zizzi, Samuel

Title: The Effects of a Physical Activity Intervention for Weight Loss on Self-Esteem and Body Image 


\section{Appendix B}

\section{Review of Literature}

With the multitude of research undertaken in the last few decades, exercise has been shown to positively affect a number of psychological variables including depression and anxiety (Blumenthal et al., 1999). As well, physical activity is beneficial in improving self-concept and self-esteem, an idea that has been validated in both adult and child populations (Dishman et al., 2006; Raglin, 1990). As physical activity can decrease the symptoms of depression, and low selfesteem is often a predictor of onset of depression, some have therefore hypothesized that the relationship between exercise and depression relief may ultimately be due to the mediating effects of self-worth and self-image (Dishman et al., 2006).

Self-esteem is also related to the satisfaction or dissatisfaction a person has with his or her appearance. Body image has traditionally received much attention due to its association with eating disorders (Furnham, Badmin, \& Sneade, 2002), and more recently because of the increasing prevalence of obesity in the United States and elsewhere (Foster, Wadden, \& Vogt, 1997). Some research has shown improved body image and self-esteem as the result of weight loss maintenance, while others support the finding that adjustments in body image can occur independently of change in weight (Foster et al., 1997; Nir \& Neumann, 1995). It may be that adoption of an exercise routine alone can cause sufficient increases in self-efficacy and selfesteem, which in turn affect perceptions of body image regardless of weight. However, the interactions of these different variables are complex, and require individual and in-depth attention before such a hypotheses can be stated with confidence. The following will review literature in the areas of: a) physical activity and self-esteem; b) physical activity and body 
image; and c) weight loss, self-esteem, and body image, and d) qualitative analysis of changes to self-esteem and body image after weight loss or physical activity intervention.

\section{Physical Activity and Self-Esteem}

Because self-esteem is a large part of psychological growth during adolescence, it is no wonder there is a breadth of research on how physical activity during the childhood and teenage years affects one's sense of worth (Dishman et al., 2006). Kirkcaldy, Shephard, and Siefen (2002) found several substantial relationships between physical activity and psychological wellbeing, including positive self-image and increased feelings of self-efficacy and mastery among 988 German teenagers who participated in sports. However, they caution that causality should not be inferred, as poor self-image could be due to physical inactivity, rather than the converse. Additional benefits to activity included increased opportunities for discussion regarding selfesteem and body image, and positive feedback from peer groups due to enhanced fitness and social interactions, both of which serve to protect from depressive cognitions

Dishman et al. (2006) also found sport participation to be negatively related to risk of depression and positively to physical concept, and determined that appearance also plays an important role in self-esteem growth amongst adolescent girls. In a correlational, cross-sectional study of 1250 girls, the researchers used a structural equation model that examined the mediating effects of global physical self-concept on the relationships between physical activity and sport participation, self-esteem, and depression symptoms. Overall, the model accounted for 51\% of the variability in self-esteem. Interestingly, the researchers concluded that perceptions of appearance were not related to the influence of physical activity on worth. In contrast, Sands, Tricker, Sherman, Armatas, and Maschette (1996) reported that preadolescent females $(N=61)$ who engaged in exercise less frequently showed lower self-esteem and more negative body 
image. However, the correlation between body image dissatisfaction and self-esteem was not significant $(r=-.28, \mathrm{p}<.053)$. This is partially supported by Tremblay, Inman, and Willms (2000), who found through regression analysis that among a large sample of Canadian children $(N=6,923)$ those who were more physically active had higher self-esteem $(p<.001)$.

In a study conducted through the Y.M.C.A. (Collingwood \& Willett, 1971), a sample of five obese teenage males was shown to have experienced an increase in self-esteem and improved attitude towards their appearance after a three-week physical training program. The subjects showed a significant increase both in measures of self-concept $(p=.05)$ and selfacceptance $(p=.05)$ However, a multidisciplinary weight-loss program involving obese teenagers found that self-esteem was negatively impacted (Stice, Cameron, Hayward, Taylor, \& Killen, 1999); it should be noted though, that exercise was not the focus of this study, and decrease in self-worth was instead correlated with dieting and other weight-loss strategies.

Using a physical activity intervention package analyzing the self-esteem of adolescent and preadolescent girls $(N=161)$, Boyd and Hrycaiko (1997) ran an analysis of variance and found that the strongest effects were on physical abilities self-concept $(F(1,51)=22.657, \mathrm{p}<$ .01 ), with a much weaker relationship being found regarding physical appearance self-concept $(F(1,51)=4.573, \mathrm{p}<.05)$. The authors suggest that the findings support the notion that physical skill is unrelated to physical attractiveness. However, they note that for young children, the different facets of self-esteem may not be differentiated as well as for older children, and thus modifications in one area may generalize to another aspect of the self-concept. Due to these differences in self-esteem changes among age groups, it is suggested that future research and interventions be separated by the needs of varying age categories, as adolescents and preadolescents seem to require focal points on different domains of self-esteem. 
Another study analyzing the association between physical activity and self-esteem among adolescent girls found similar results; one difference was that it also examined the use of cooperative versus competitive activities (Marsh \& Peart, 1988). In a study of Australian girls ages 11-14 $(N=137)$, it was found that mean physical ability and physical appearance selfconcept scores were higher for the groups utilizing cooperative fitness programs (4.40 and 3.57, respectively) than for those using competitive programs $(3.90 ; 3.00)$; in fact, the scores for the competitive group were lower compared to pretest scores. Another significant $(p<.01)$ finding showed increased fitness level was correlated with enhanced physical ability self-concept, though it was argued that the competitive arena likely increased fitness but decreased physical self-concept due to the natural evaluation of these abilities with others' in the group.

While self-esteem may be highly influenced during adolescence it is still malleable in adulthood, and exercise may impact how older subjects feel about themselves as well. Trujillo (1983) also found increased fitness and self-esteem levels using separate activity interventions involving running and weight lifting. In a sample of 35 females, significant increases in selfesteem were found, while a control group exhibited a decrease in self-esteem. The author asserted that the while all findings were correlational, they lend support to the interrelated association between self-esteem, physical fitness, and body image.

Descriptive research by Tiggemann and Williamson (2000) found that overall greater amounts of exercise led to higher reports of self-esteem among men and women $(N=252)$ who participated for health and fitness reasons rather than for weight loss or physical appearance. However, for females aged 16-21 increased physical activity corresponded to lower self-esteem $(r=-.30, z=6.32, p<.0001)$, which the authors hypothesized may be due to strong sociocultural influences placed on young women in relation to the body and one's appearance. 
Tiggemann and Williamson (2000) employed an instrument for global self-esteem in order to measure feelings of self-worth in participants, as do many studies examining changes in self-esteem from increased activity. A meta-analysis by McDonald and Hodgdon (1991) found moderate changes in global self-esteem levels from exercise, which would support the use of general measures. However, the assumption that changes in general self-esteem will result from participation in physical activity is not supported by some studies, which claim that the magnitude of change in global self-esteem from exercise is actually lower than that found with other constructs such as state anxiety and depression (Calfas \& Taylor, 1994; Craft \& Landers, 1998; Long \& van Stavel, 1995; McAuley, Blissmer, Katula, Duncan, \& Mihalko, 2000). A recent meta-analysis found small but significant effects $(d=+0.23)$ between exercise participation and global self-esteem (Spence, McGannon, \& Poon, 2005). The authors concluded that while participation in physical activity may produce a small amount of change in overall feelings of worth, it is much more influential on domain-specific levels of self-esteem (i.e., physical self-worth).

Sonstroem and Morgan (1989) developed a hierarchical model examining the interactions between exercise and self-esteem that features domain-specific constructs leading to predictions of global self-esteem known as the Exercise and Self-Esteem Model (EXSEM; see Figure 1). Global self-esteem is featured in the top tier of the model, followed by physical self-competence and physical acceptance in the middle tier, and finally physical self-efficacy in the lowest tier. The constructs within the lower tiers are said to have a small effect on the general feelings of self-esteem in the top tier, but are more closely related to the specifics of a current situation or context. The EXSEM was proposed in part to help determine the mechanisms by which exercise leads to changes in self-esteem. The authors hypothesized that changes in physical fitness lead to 
increased self-efficacy and physical competence, which in turn leads to an enhanced perception of overall self-worth.

Support for the EXSEM was provided by Sonstroem, Harlow, Gemma, and Osborne (1991), who found that feelings of global self-esteem were increased due to enhanced selfefficacy on specific physical tasks, albeit through the intervening construct of perceived physical competence. A confirmatory factor analysis determined that the Exercise and Self-Esteem Model accounted for $29 \%$ of the variance in self-esteem among a sample of 145 men and women. Thus, the authors determined that the model is useful for examining how exercise influences selfperceptions, which may then in turn generalize to overall self-esteem. This statement corroborates the impact of activity on self-perception put forth by Fox and Corbin (1989) in relation to self-esteem.

McAuley, Mihalko, and Bane (1997) examined the relationships among both global and specific levels of self-esteem over a twenty-week physical activity program $(N=114)$. Domainspecific levels (physical condition and physical self-worth) showed the greatest change $(t=4.17$, $p<.0001, \mathrm{ES}=.41$ and $t=5.4, p<.0001, \mathrm{ES}=.54$, respectively) while a small but significant increase was seen in global self-esteem $(t=3.09, p<.003, \mathrm{ES}=.22)$. The authors suggest that future research should focus on exercise as a means to increase positive perceptions of the physical domain, as general feelings of self-worth may exhibit the least amount of change due to exercise.

Within interventions to increase physical activity levels, determining the pathways to changes in self-esteem can be problematic; multiple explanations can exist for why psychological constructs differ after treatment. Palmer (1995) found that subjects assigned to an eight-week walking group showed increased levels of both fitness and self-esteem compared to 
women in a control (non-walking) group. However, the author concluded that changes in selfesteem may not have been due solely to the activity intervention; other factors such as enhanced self-efficacy, task completion, or social interactions may have been influential on feelings of self-worth as well.

DiLorenzo, et al. (1999) found increases in the related construct of self-concept (Wilks' $\lambda$ $=0.745, F(2,64) 510.97, p<.0001)$ after a 12-week aerobic exercise intervention $(N=82)$. In addition to increased fitness levels, the authors hypothesized that increased social support due to the nature of the intervention could have resulted in better self-concept. In addition, changes in body composition and subsequent enhanced body image may also have affected psychological outcomes. So, while increased physical activity may be associated with feelings of worth, there may be other variables that require consideration when examining changes in self-esteem.

Physical activity has thus been shown to affect self-esteem levels across many ages and through various forms of activity. While exercise has been correlated with changes in physical domain-specific areas, differences in global self-esteem have not been as consistent. The current study will attempt to examine the changes in both physical and global self-esteem among adults participating in an intervention using physical activity as one means to produce weight loss. Previous research has shown it is likely that participants will enhance physical self-perceptions with increased physical activity; an additional hypothesis for this study is that resulting weight loss from increased physical activity will also enhance global self-esteem above and beyond what might be found with exercise alone. If self-esteem is indeed affected by changing exercise levels and body composition, it seems likely participants may modify perceptions of their bodies as well.

Physical Activity and Body Image 
Individuals reporting lower levels of self-esteem typically report higher dissatisfaction with their bodies, and this dissatisfaction with appearance may mediate the relationship between one's self-esteem and weight (Bezner, Adams, \& Steinhardt, 1997; Friedman, Reichmann, Costanzo, \& Musante, 2002; Furnham et al., 2002; Miller \& Downey, 1999). Some research has shown that views regarding one's body may appear even before the onset of puberty, when one's self-esteem is central to identity formation (Sands et al., 1996). Matz, Foster, Faith, and Wadden, (2002) found that among a sample of 79 obese women seeking weight loss, self-esteem was the largest predictor of body image dissatisfaction $(r=.408, p<.01)$. The authors therefore posit that overall feelings of self-worth may be intricately entwined with evaluations of the physical self.

A study by Depcik and Williams (2004) examined the effect of a weight lifting program on body image dissatisfaction among college-aged women with body image disturbances $(N=$ 96). It was found that body image dissatisfaction was negatively related to weight lifting ( $F(2$, $27)=5.67, p<.05$ ), and the women participating in the weight lifting program reported increased body image satisfaction (from a mean pretest score of 3.19 to a mean posttest score of 3.40) compared to women not participating (mean scores were maintained at 3.10). The authors hypothesized that body satisfaction was increased due to enhanced feelings of strength and thus better physical self-perceptions and esteem. Their results, and previous research, support the idea that physical activity influences self-perceptions; these improved perceptions may thus lead to enhanced body image (Bartlewski, Van-Raalte, \& Brewer, 1996; Hayes, Crocker, \& Kowalski, 1999).

Bartlewski et al. (1996) followed female college students in an aerobic exercise course and a sociology course over a semester, and found that only students participating in the exercise 
class had increased body esteem. This was supported by further research showing that aerobic activities such as step aerobics and running can increase body satisfaction (Koff \& Bauman, 1997). Another study compared the effects of a weight training intervention and a walking intervention among previously inactive women (Tucker \& Mortell, 1993). It was found that women participating in the weight training program $(N=60)$ showed greater improvements in body image than did women in the walking program. In addition, among the weight training group, women with lower baseline body image dissatisfaction exhibited the greatest increases in satisfaction post-intervention.

Henry, Anshel, and Michael (2006) examined body image before and after a physical activity intervention comparing aerobic exercise $(n=23)$, interval circuit training $(n=28)$, and a control group $(n=21)$. Among college-aged women, the interval circuit training condition was found to be the most effective for improving body image as well as VO2max and body composition. Tukey pairwise comparisons determined that the body image variables negative affect $(\mathrm{Q}=4.11, \mathrm{p}<.013)$ and health and fitness evaluation $(\mathrm{Q}=3.91, \mathrm{p}<.019)$ had the largest effect on differences between the three groups. This supports previous research by Perry et al. (2002) showing that an intervention utilizing both aerobic and anaerobic methods can improve body image measures.

Williams and Cash (2001) found circuit weight training to be an effective intervention for increasing body image amongst a mixed-gender group. The authors sampled 27 females and 12 males, and grouped them according to current levels of aerobic activity. After the 6-week program both genders saw greater body satisfaction, regardless of aerobic activity levels. Those who completed the weight training saw improvements on four measures of body image: the Appearance Evaluation subscale of the Multidimensional Body-Self Relations Questionnaire 
$(F(1,76)=6.41, p<.02)$, the Body Areas Satisfaction Scale $(F(1,75)=31.99, p<.001)$, the Social Physique Anxiety Scale $(F(1,74)=4.23, p<.05)$, and the Perceived Physical Ability subscale of the Physical Self-Efficacy Scale $(F(1,76)=14.46, p<.001)$. Similar results examining effects of weight training on body image in males have been reported elsewhere (James, 1982).

It is interesting to note that gender may be an additional variable in the relationship between self-esteem and body image. Many males wish to gain weight, while most females desire to be thinner, and self-esteem has been highly correlated with body image satisfaction in females, but not consistently in males (Furnham et al., 2002; Rodin, Silberstein, \& StriegelMoore, 1985). A study by Bezner et al. (1997) did find that body dissatisfaction exists in men, and the authors concluded that as men get older there is often a natural increase in weight but no adjustment of ideal body shape with age. Kashubeck-West, Mintz, and Weigold (2005) reported that overall body dissatisfaction is similar for men and women when controlling for desire to lose weight.

In addition, a study by Grant and Fodor (1986) found that self-esteem of high school females $(N=169)$ was related to perception of attractiveness of one's body, whereas self-esteem of males was linked to the view of the body as effective and functional. Therefore, it should come as no surprise that females have higher body dissatisfaction and greater risk of disordered eating.

While development of an eating disorder is often paired with weight control habits relating to food, it is also possible for excessive exercise to be used as a means to maintain or lose pounds. In Furnham et al.'s (2002) examination of reasons for exercise and body image, females reported exercising for negative reasons such as mood and weight control more often 
than did males, who reported exercising more frequently for fitness and health means. These results support McDonald and Thompson's (1992) findings that women exercised for concerns such as weight, muscle tone, and attractiveness to a greater degree than men. These motivations for physical activity were generally found to be indicative of eating disturbances and body dissatisfaction in both genders, while exercising for health or enjoyment were associated with increased self-esteem.

Another study focused on reasons for exercise categorized motivation as being "foodrelated," and "non-food related," with those who exercised for reasons directly tied to food consumption falling into the first category, and those who did not report such behavior in the second (Hubbard, Gray \& Parker, 1998). Those women who utilized exercise as a means for weight control were compared to "obligatory exercisers," or persons who show a subjective need to exercise and are loathe to cease activity for any reason; these exercisers are likely to have psychological traits similar to persons suffering from an eating disorder (Pasman \& Thompson, 1988). Hubbard et al. (1998) hypothesized that women who exercised specifically to counterbalance caloric intake would have higher rates of body image dissatisfaction, disordered eating, and lowered self-esteem. In fact, this was found to be the case, helping to show that while exercise can be used to increase body image satisfaction and self-esteem, it can also have negative consequences in some cases.

Sonstroem, Harlow, and Josephs (1994) found that women who exercised more frequently scored lower on scales of physical self-worth than did women who were not regular exercisers. This is supported by the finding that women who exercised for six or more hours per week were more discontent with their bodies (Leveillee, Sonstroem, \& Riebe, 1994). It may be 
then that an over-emphasis on exercise can lead to negative perceptions and increased selfconsciousness (Brumberg, 1988).

Interestingly, exercise frequency has also been studied in relation to social physique anxiety, which has been associated with excessive physical activity (Frederick \& Morrison, 1996). However, in a study of 168 college-aged females, Russell and Cox (2003) determined that there was no relationship between social physique anxiety and frequency of exercise, nor with self-esteem $(F(1,167)=1.09, \mathrm{p}=.30)$. The researchers suggest additional longitudinal studies examining exercise behavior and whether this can lead to changes in social physique anxiety over time. As self-esteem has been correlated with social physique anxiety (Martin, Engels, Wirth, \& Smith, 1997), it can be assumed that if regular exercise were to reduce this concern, then it would also increase attributions of self-confidence and efficacy.

Since body image and self-esteem seem to be so closely related, changes in one concept could produce changes in another and vice versa. Aerobic and anaerobic activities have been found in previous research to effect satisfaction with one's body image (Henry, Anshel, \& Michael, 2006), in both males and females of various ages. It has been found that men and women often participate in physical activity for differing reasons, some of which can negatively affect body image perception (i.e., to offset caloric intake), and that women report exercising for these reasons more frequently (Furnham, Badmin, \& Snead, 2002; McDonald \& Thompson,1992).

Gender effects on body image will not be examined in the present study, as differences found in previous research may not be as applicable to the current subject pool. Participants in the Weight Management Program (WMP) are of a similar physical make-up and motivation to be 
physically active is defined by the nature of the intervention: enhanced physical activity and weight loss.

\section{Weight Loss, Self-Esteem, and Body Image}

If it is the case that physical activity causes a reduction in body weight, then it may be hard to determine whether it is the change in one's physical appearance (and thus a body closer to the social "ideal"), or the psychological benefits gained from adoption of regular exercise (feelings of control, increased confidence, etc.) that matter more to changes in self-perceptions. Braet (2006) found that global self-esteem increased over a 2-year post-intervention period in a sample $(n=122)$ of children ages $7-17$ who participated in an in-patient obesity treatment program, and overall psychopathology was lower after treatment as compared to baseline levels (mean scores were 56.72 at pre-test, 55.16 at post-test, and 54.48 at 2-year follow-up). While $24 \%$ of children continued to lose weight after the program, all others showed some weight regain. Interestingly, the author found that exhibiting characteristics of an eating disorder was a strong negative predictor of weight loss success, and also affected changes in global self-esteem.

Other studies have examined the use of "undieting" approaches, focusing on selfacceptance and increased self-esteem through changes in eating patterns. Polivy and Herman (1992) found while changes in efficacy were reported, body dissatisfaction remained high in females $(N=18)$; so, while there were significant increases in self-esteem $(t(14)=3.62, p<$ $.003)$, there was no significant change in weight over the course of the intervention $(t(14)=1.37$, $p>.10$ ). Therefore, the lack of enhanced body satisfaction was deemed to be because of a lack of weight loss and the unrealistic idea of enhanced body acceptance without such a change.

However, findings from Rosen, Orosan, and Reiter (1995) showed an improvement in body image satisfaction without corresponding weight loss, leading some to conclude that body 
image may be malleable independent of changes in weight. Similar results were found in the study of a "health-centered" non-diet wellness program, that saw participants improve on selfesteem and body image measures over a one-year period despite no concurrent weight loss (Bacon et al., 2002). Foster, Wadden, and Vogt (1997) reported similar results in a study of obese women during a weight loss treatment program, in that improvements in body image were not found to be related to weight loss $((r=-.25, p=.09$ for Appearance Evaluation; $r=-.27, p=$ .06 for Body Areas Satisfaction). The researchers postulated that the change in body image may have instead been due to the cognitive-behavioral aspect of the treatment program itself.

Adami et al. (1998) reported data showing that weight loss among obese women is associated with change in body image toward levels found in average-weight control subjects (mean score of 8.9 for post-obese women, mean score of 6.3 for non-obese women, $p<.0001$ ). However, the authors also found that satisfaction with body image after weight loss was greater for adults who became obese rather than for those who had been overweight since childhood. This was attributed to the fact that body image construct forms in childhood, leading to a selfimage as "fat" and making it hard to change perceptions later, even with successful weight loss.

Friedman et al. (2002) suggested utilizing intervention programs that focus on both weight reduction and body-image therapy for treatment of extremely overweight populations. The authors posited that better self-understanding of one's body and dissociation of weight and other aspects of the self might reduce psychological distress and facilitate weight loss. However, adding a body image component to treatment for weight loss has not consistently been shown effective. Ramirez and Rosen (2001) did not find psychological improvement or more significant weight loss after adding body-image therapy to a cognitive-behavioral weight-loss treatment 
program, however participants $(N=65)$ did exhibit improvement in body image $(F(1,57)=5.07$, $p=.028)$ and self-esteem $(F(1,57)=17.99, p=.000)$.

Another study by Nauta, Hospers, and Jansen (2001) found that after a cognitive treatment program for obese women $(N=74)$, body image $(F(1,57) 57.84, p<.01)$ and selfesteem $(F(1,57) 547.26, p<.001)$ were improved upon follow-up one year later. However, participants who gained weight in the interim were as successful in changing psychological mood as were participants who lost weight. Thus, it was concluded that psychological well-being was not related to weight loss, and the authors recommend that future studies examine whether psychological change should precede weight loss for long-term success or vice versa.

The idea that psychological outlook is not dependent on weight is somewhat supported by an examination of obese children before and after participation in a summer weight loss camp program $(N=194)$ (Gately, Cooke, Butterly, Knight, \& Carroll, 2000). The program consisted of multiple approaches to weight loss, including physical activity, diet, and behavioral modification. While the authors found significant changes in psychological variables including body esteem and body image $(p<.001)$, further multivariate analysis revealed that these changes were not dependent on reduction in body mass, but on time spent at the camp. It was concluded that the program as a whole influenced the changes in psychosocial factors. However, Barton, Walker, Lambert, Gately, and Hill (2004) conducted a similar study among adolescents (average age of 14) at a weight loss camp and found that positive cognitive changes (specifically automatic thoughts about exercise and appearance) were largely due to reduction in weight, and that these changes were strongly correlated with increases in global self-worth.

Still, conflicting results were found by Cameron (1999), who determined that enrollment in weight management programs may serve to decrease self-esteem in children. Among a sample 
$(N=60)$ of obese children ages $10-15$, the author concluded there was no significant change in weight following participation in a weight management program, and that self-esteem was decreased $(F=3.98, p=.05)$ due to feelings of embarrassment, inadequacy, and failure produced as a result of the program. The author suggests further research promoting weight loss interventions for youth that teach coping resources and enhance self-perceptions.

In addition to weight loss influencing self-esteem, some studies have examined selfesteem and how it can conversely predict success in attempts at weight reduction. Nir and Neumann $(1995)$ postulated that obese women $(N=66)$ rating highest in self-esteem would maintain weight loss longer, and found that the higher self-esteem was rated, the less weight was regained during a follow-up period $(r=-.18$ for self-esteem and weight gain and $r=.21, p<.05$ for self-esteem and months of weight loss maintenance). The authors hypothesized that it is greater amounts of self-control related to higher self-esteem that led to better perseverance in weight loss. The recommendation was then made that weight loss programs be designed for different personality constructs; specifically low self-esteem individuals be provided with programs of increased duration, and those with high self-esteem receive retraining at periodic intervals.

Teixeira et al. $(2002)$ found low self-esteem $(p<.008)$ and high body dissatisfaction $(p<$ .002) to be predictors of less weight loss among 136 women in a 4-month lifestyle behavioral weight reduction program. The authors also promote using associations between such psychological variables as self-esteem to match participants to programs, as well as for use in questionnaires to establish readiness to begin weight loss treatment.

van Gemert, Severeijns, Greve1, Groenman, and Soeters (1998) found that self-esteem was the best predictor of weight loss among a sample of morbidly obese adults who underwent 
various forms of weight-loss surgery $(N=66)$, and predicted $15.4 \&$ of the variance in outcome $(p<.05)$. The authors hypothesized that morbidly obese individuals with low self-esteem may exhibit the greatest psychological suffering and thus maintain greater motivation to lose weight and adhere to treatment. After surgery the authors found that psychological factors did improve, and these changes were attributed mainly to weight loss. Enhanced self-esteem and psychological functioning were found even if the participant suffered surgical complications. A qualitative study of the psychological effects of weight-loss surgery found that both gastric bypass and jejunoileal bypass produced significant weight loss among obese participants $(N=86)$ with less negative psychological disturbance than attempts at weight loss made previously through diet (Halmi, Stunkard, \& Mason, 1980). In addition, more than half of the participants increased levels of positive emotions such as self-confidence after surgery. The authors hypothesized that biological changes in the body may be responsible for a "normalization" of eating patterns, which in turn may affect emotional stability.

It is important to note that of the aforementioned studies examining weight loss and changes in self-esteem and body image, few utilized an exercise program as a primary intervention. The two most widely-used means to weight reduction are through changes in physical activity levels and changes in eating habits. Research often supports the idea that dieting can be harmful however, possibly even contributing to weight gain and obesity (Polivy \& Herman, 1992). A study by French, Story, Downes, Resnick, and Blum (1995) found that adolescents who engaged in frequent dieting regimens were more likely to have negative body image, emotional stress, and high ratings on measures of suicide risk.

Polivy, Heatherton, and Herman (1988) found persons with high self-esteem may be more successful due to better coping skills for excessive eating and other stressors. However, the 
authors thought it more likely that "failures" in weight loss attempts through dieting can cause decreases in self-esteem, which then lead to further distorted eating patterns and possibly binge eating. So, one can safely assume that if dieting is not the ideal route to take in increasing selfesteem and body image satisfaction through weight loss, then adoption of regular exercise would be more likely to produce positive results with less psychological and cognitive disturbance.

Weight loss can be achieved through various means, including dieting, exercise, surgery, or any combination of these modalities. It has been more common in previous literature to examine changes in self-esteem and body image after weight loss surgery, through changes in eating patterns, or overall "wellness" and cognitive-behavioral interventions for weight loss. Fewer studies have been conducted utilizing a more holistic intervention focused mainly on increased exercise for weight loss. The WMP intervention combines healthy eating and behavioral changes along with physical activity in order to optimize weight loss outcomes. Examining changes in the psychosocial variables of self-esteem and body image through an allencompassing and practical intervention like the WMP may help provide evidence that such a program is not only beneficial for mental health, but can also offer a healthier alternative to potentially dangerous yet common weight loss practices such as surgery.

\section{Qualitative Research}

Looking at changes in psychosocial variables like self-esteem and body image is often completed using quantitative research such as survey methods. However, results are often limited in scope because the meaning that participants ascribe to these changes and what caused them may be overlooked. Qualitative analysis is one way to determine participants' perceptions of weight change and self-esteem, and the effect that physical activity might have on these constructs. 
Unfortunately, qualitative research examining psychosocial changes with initiation of physical activity and weight loss has been infrequent. Thus, while it is well documented that participants often experience increases in self-esteem and body image satisfaction after beginning a physical activity or weight loss intervention (Depcik \& Williams, 2004; Nauta, Hospers, and Jansen, 2001; Palmer, 1995; Tiggemann \& Williamson, 2000), it is less clear what participants' perceptions are as to the mechanisms that are driving such changes. In addition, it is important to ascertain what participants' expectations are from an intervention, and whether they believe such expectations have been met at the cessation of a program. With the decreases in physical activity levels often seen after an intervention ends (Marcus et al, 2006), it is not surprising that a large percentage of participants losing weight regain or exceed their pretreatment weight within three to five years (Byrne, Cooper, \& Fairburn, 2003). Therefore, understanding what participants think about their experience in a weight loss intervention and what was helpful for creating and maintaining behavior change is extremely important.

Crone, Smith, and Gough (2005) used grounded theory methodology $(n=18)$ to conceptualize a framework for the relationship between physical activity and mental health. A core category of "self-acceptance" was identified, with conditional themes of social support, social network, culture, and environment. The authors determined that the experience of exercise itself should be emphasized, as irrespective of outcomes such as weight loss. Physical activity alone may be aid people in feeling content in who they are at the present moment, and deemphasize a focus on a future self. It should be noted however, that the participants in Crone et al.'s (2005) study were referred by general practitioners for physical health reasons, and may not have qualified as obese. Thus, the experiences of these individuals could be quite different from those with a significant amount of weight to be lost. Still, the authors recommended that 
further interpretive research be conducted, so as to better determine the mechanism for mental health promotion through physical activity.

One qualitative research study attempted to examine the weight loss experience and participants' feelings through interviews and focus groups with eighteen obese men and women (Bidgood \& Buckroyd, 2005). While not currently enrolled in a weight loss intervention, the self-referred participants all had or were trying various treatment modalities in order to lose weight. The authors noted that many participants exhibited low self-esteem and poor body image, and most had become socially withdrawn from others. These psychosocial issues may be partially attributed to prejudice and stigmatization, one of five sub-themes identified through thematic analysis of the interview transcripts. Many participants discussed restricting their lifestyle and "hiding" from the general public due to widely held negative views on obesity. This stigmatization also impacted the effectiveness of weight loss treatments, as many participants experienced reduced physical activity levels and increased eating upon withdrawal from society. In addition, participants felt that their concerns as obese individuals were not heard or understood by the general public, causing some to again be averse to social and community settings, including fitness centers.

Another sub-theme determined by Bidgood and Buckroyd (2003) was that the lifestyle change required for long-term weight loss maintenance requires on-going help. This is an important factor for intervention design, as programs should incorporate information and strategies for maintaining weight loss after cessation of treatment. In fact, a qualitative analysis of obese African-American women was conducted in order to design a weight loss intervention targeting this population (Befort, Thomas, Daley, Rhode, \& Ahluwalia, 2008). The authors found that the women desired treatments incorporating information on long-term changes and lifestyle 
modifications rather than medications or fad diets. With enhanced education, perhaps greater numbers of participants will have the self-efficacy to be able to continue with established physical activity levels and proper nutrition guidelines once the intervention is over. This sentiment was echoed by Sarlio-Lanteenkorva (2000), who found that for women $(n=9)$ who had lost weight and kept it off for at least seven years, weight maintenance was regarded as a constant battle that required proactive strategies to prevent regain and constant monitoring.

Sarlio-Lanteenkorva (2000) also noted that the women felt a tension between who they were in the present, and their obese selves of the past. Thus, despite commenting on improvements in self-esteem and health, the women still felt as though they were different from other people. It could be hypothesized that body image does not change as rapidly as self-esteem with weight loss, and thus these women still held negative views of their appearance despite an overall sense of improvement. So, while self-esteem may be enhanced with weight loss, perhaps it is necessary to understand more about why individuals feel better about themselves, and what specific components of their self-concept change.

Increased self-confidence and self-esteem could be factors that help participants adhere to the nutritional and physical activity guidelines utilized in a weight management program. Shiner, Whitley, Citters, Pratt, and Bartels (2008) interviewed eight participants in a health promotion intervention for persons with mental illness, and found that improved self-confidence due to participation was often perceived as one of the most helpful aspects of the intervention. In addition, participants described individualization of the intervention and positive relationships with intervention staff as additional factors that were helpful in promoting health improvements. Unfortunately, because the sample was comprised of individuals with serious mental illness, the 
results have limited generalizability to general populations; however, the participants were all considered obese at the initiation of the intervention, so some similarities may be found.

Another qualitative examination of a weight loss intervention also determined that individualized programs could help participants to maintain nutritional and physical activity behavior change (Kayman, Bruvold, \& Stern, 2001). The authors interviewed obese women who regained weight after successful weight loss $(n=44)$, women who successfully lost weight and maintained the weight loss $(n=30)$, and a control group of non-obese women who had always been of average weight $(n=34)$. It was found that the maintainers and control group confronted problems directly and developed personal strategies to help themselves, while the relapse group did not confront problems and instead ate unconsciously due to emotions. In addition, while most maintainers and control group participants exercised regularly and utilized means of social support, few of the relapsers did; thus, the authors recommended development of individualized treatment programs in order to enhance coping skills, use of social support, and exercise behaviors.

So, understanding what participants expect from an intervention, and what they consequently view as being helpful after treatment cessation, are both important for designing weight loss programs. In addition, understanding the psychological as well physical benefits of physical activity and weight loss can also be useful in the creation of interventions, as these constructs can then be targeted and enhanced. Increased self-esteem is one such benefit of physical activity and weight loss, and may not only help participants build self-efficacy and feel good about themselves, but adhere to positive changes in health for the long-term. Further qualitative research is warranted in order to better understand how to help participants build self- 
Qualitative Analysis of Weight Loss 53

esteem during interventions for weight loss and use this improved sense of being in order to maintain behaviors across the lifespan. 


\section{References}

Adami, G. F., Gandolfo, P., Campostano, A., Meneghelli, A., Ravera, G., \& Scorpinaro, N. (1998). Body image and body weight in obese patients. The International Journal of Eating Disorders, 24, 299-306.

Bacon, L., Keim, N. L., Van Loan, M. D., Derricote, M., Gale, B., Kazaks, A., et al. (2002). Evaluating a 'non-diet' wellness intervention for improvement in metabolic fitness, psychological well-being and eating and activity behaviors. International Journal of Obesity, 26, 854-865.

Bartlewski, P. P., Van-Raalte, J. L., \& Brewer, B. W (1996). Effects of aerobic exercise on the social physique anxiety and body esteem of female college students. Women in Sport and Physical Activity Journal, 5, 49-62.

Barton, S. B., Walker, L. L., Lambert, G., Gately, P. J., \& Hill, A. J. (2004). Cognitive change in obese adolescents losing weight. Obesity Research, 12, 313-319.

Befort, C., Thomas, J., Daley, C., Rhode, P., \& Ahluwalia, J. (2008). Perceptions and beliefs about body size, weight, and weight loss among obese African American women: A qualitative inquiry. Health Education \& Behavior, 35, 410-426.

Bezner, J. R., Adams, T. B., \& Steinhardt, M. A. (1997). Relationship of body dissatisfaction to physical health and wellness. American Journal of Health Behavior, 21, 147-155.

Bidgood, J. \& Buckroyd, J. (2003). An exploration of obese adults' experience of attempting to lose weight and to maintain a reduced weight. Counselling and Psychotherapy Research, 5, 221-229.

Blaine, B. E., Rodman, J., \& Newman, J. M. (2007). Weight loss treatment and 
psychological well-being: A review and meta-analysis. Journal of Health Psychology, 12, $66-82$.

Blumenthal, J. A., Babyak M. A., Moore K. A., Craighead W. E., Herman S., Khatri P., et al. (1999). Effects of exercise training on older patients with major depression. Archives of Internal Medicine, 159, 2349-2356.

Booth, F. W., \& Chakravarthy, M. V. (2002, March). Cost and consequences of sedentary living: New battleground for an old enemy. President's Council on Physical Fitness and Sports Research Digest, pp. 1-8.

Boyd, K. R., \& Hrycaiko, D. W. (1997). The effect of a physical activity intervention package on the self-esteem of pre-adolescent and adolescent females. Adolescence, 32, 693-708.

Braet, C. (2006). Patient characteristics as predictors of weight loss after an obesity treatment for children. Obesity, 14, 148-155.

Brumberg, J. J. (1988). Fasting girls: The emergence of anorexia nervosa as a modern disease. Cambridge, MA: Harvard University Press.

Byrne, S., Cooper, Z., \& Fairburn, C. (2003). Weight maintenance and relapse in obesity: A qualitative study. International Journal of Obesity, 27, 955-962.

Calfas, K. J., \& Taylor, W. C. (1994). Effects of physical activity on psychological variables in adolescents. Pediatric Exercise Science, 6, 406-423.

Cameron, J. W. (1999). Self-esteem changes in children enrolled in weight management programs. Pediatric Nursing, 22, 75-85.

Collingwood, T. R., \& Willett, L. (1971). The effects of physical training upon selfconcept and body attitude. Journal of Clinical Psychology, 27, 411-412. 
Craft, L. L., \& Landers, D. M. (1998). The effect of exercise on clinical depression and depression resulting from mental illness: A meta-analysis. Journal of Sport \& Exercise Psychology, 20, 339-357.

Crone, D., Smith, A., \& Gough, B. (2005). "I feel totally alive, totally happy and totally at one": A psycho-social explanation of the physical activity and mental health relationship from the experiences of participants on exercise referral schemes. Health Education Research, 20, 600-611.

Depcik, E., \& Williams, L. (2004). Weight training and body satisfaction of bodyimage-disturbed college women. Journal of Applied Sport Psychology, 16, 287-299.

DiLorenzo, T. M., Bargman, E. P., Stucky-Ropp, R., Brassington, G. S., Frensch, P. A., \& LaFontaine, T. (1999). Long-term effects of aerobic exercise on psychological outcomes. Preventive Medicine, 28, 75-85.

Dishman, R. K., Hales, D. P. Pfeiffer, K. A., Felton, G., Saunders, R., Ward, D. S., et al. (2006). Physical self-concept and self-esteem mediate cross-sectional relations of physical activity and sport participation with depression symptoms among adolescent girls. Health Psychology, 25, 396-407.

Foster, G. D., Wadden, T. A., \& Vogt, R. A. (1997). Body image in obese women before, during, and after weight loss treatment. Health Psychology, 16,, 226-229.

Fox, K. R. \& Corbin, C. B. (1989). The physical self-perception profile: Development and preliminary validation. Journal of Sport \& Exercise Psychology, 11, 408-430.

Frederick, C. M., \& Morrison, C. S. (1996). Social physique anxiety: Personality constructs, motivations, exercise attitudes, and behaviors. Perceptual and Motor Skills, 82, 963-972. 
French, S. A., Story, M., Downes, B., Resnick, M. D., \& Blum, R. W. (1995). Frequent dieting among adolescents: psychosocial and health behavior correlates. American Journal of Public Health, 85, 695-701.

Friedman, K. E., Reichmann, S. K., Costanzo, P. R., \& Musante, G. J. (2002). Body image partially mediates the relationship between obesity and psychological distress. Obesity Research, 10, 33-41.

Furnham, A., Badmin, N., \& Sneade, I. (2002). Body image dissatisfaction: Gender differences in eating attitudes, self-esteem, and reasons for exercise. The Journal of Psychology, 136, 581-596.

Gately, P. J., Cooke, C. B., Butterly, R. J., Knight, C., \& Carroll, C. (2000). The acute effects of an 8-week diet, exercise, and educational camp program on obese children. Pediatric Exercise Science, 12, 413-423.

Grant, C. L., \& Fodor, I. G. (1986). Adolescent attitudes toward body image and anorexic behavior. Adolescence, 21, 269-281.

Halmi, K. A., Stunkard, A. J., \& Mason, E. E. (1980). Emotional responses to weight reduction by three methods: Gastric bypass, jejunoileal bypass, diet. The American Journal of Clinical Nutrition, 33, 446-451.

Hayes, S. D., Crocker, P. R., \& Kowalski, K. C. (1999). Gender differences in physical self-perceptions, global self-esteem, and physical activity: Evaluation of the physical selfperceptions profile model. Journal of Sport Behavior, 22, 1-14.

Henry, R. N., Anshel, M.H., \& Michael T. (2006). Effects of aerobic and circuit training on fitness and body image among women. Journal of Sport Behavior, 29, 281-303.

Hubbard, S. T., Gray, J. J., \& Parker, S. (1998). Differences among women who 
exercise for 'food related' and 'non-food related' reasons. European Eating Disorders Review, 6, 225-265.

James, R. (1982). The effect of weight training on the self-concept of male undergraduates. Sex Roles: A Journal of Research, 35, 111-122.

Kashubeck-West, S., Mintz, L. B., \& Weigold, I. (2005). Separating the effects of gender and weight-loss desire on body satisfaction and disordered eating behavior. Sex Roles, 53, $505-518$.

Kayman, S., Bruvold, W., \& Stern, J. (1990). Maintenance and relapse after weight loss in women: Behavioral aspects. The American Journal of Clinical Nutrition, 52, 800807.

Kirkcaldy, B. D., Shephard, R. J., \& Siefen, R. G. (2002). The relationship between physical activity and self-image and problem behaviour among adolescents. Social Psychiatry and Psychiatric Epidemiology, 37, 544-550.

Koff, E. \& Bauman, C. L. (1997). Effects of wellness, fitness, and sport skills programs on body image and lifestyle behaviors. Perceptual and Motor Skills, 84, 555-562.

Leveillee, C. M., Sonstroem, R. J., \& Riebe, D. (1994, June). Self-perceptions and eating disorder differences in routine and ultra adult exercisers. Paper presented at the Annual Meeting of the American College of Sports Medicine, Indianapolis, IN.

Long, B. C., \& van Stavel, R. (1995). Effects of exercise training on anxiety: A metaanalysis. Journal of Applied Sport Psychology, 7, 167-189.

Macera, C. A., Ham, S. A., Yore, M. M., Jones, D. A., Kimsey, C. D., Kohl, H .W., et al. (2005). Prevalence of physical activity in the United States: Behavioral risk factor surveillance system, 2001. Preventing Chronic Disease, 2, 1-10. 
Marcus, B. H., Williams, D. M., Dubbert, P. M., Sallis, J. F., King, A. C., Yancey, A. K., et al. (2006). Physical activity intervention studies: What we know and what we need to know: A scientific statement from the American Heart Association Council on Nutrition, Physical Activity, and Metabolism (subcommittee on physical activity); Council on Cardiovascular Disease in the Young; and the Interdisciplinary Working Group on Quality of Care and Outcomes Research. Circulation, 114, 2739-2752.

Marsh, H. W., \& Peart, N. D. (1988)._Competitive and cooperative physical fitness training programs for girls: effects on physical fitness and multidimensional selfconcepts. Journal of Sport \& Exercise Psychology, 10, 390-407.

Martin, J. J., Engels, H. J., Wirth, J. C., \& Smith, K. L. (1997). Predictors of social physique anxiety in elite female youth athletes. Women's Sport and Physical Activity Journal, 6, 29-48.

Matz, P. E., Foster, G. D., Faith, M. S., \& Wadden, T. A. (2002). Correlates of body image dissatisfaction among overweight women seeking weight loss. Journal of Consulting and Clinical Psychology, 70, 1040-1044.

McAuley, E., Blissmer, B., Katula, J., Duncan, T. E., \& Mihalko, S. L. (2000). Physical activity, self-esteem, and self-efficacy relationships in older adults: A randomized controlled trial. Annals of Behavioral Medicine, 22, 131-139.

McAuley, E., Mihalko, S. L., \& Bane, S. M. (1997). Exercise and self-esteem in middleaged adults: Multidimensional relationships and physical fitness and self-efficacy influences. Journal of Behavioral Medicine, 20, 67-83.

McDonald, D. G., \& Hodgdon, J. A. (1991). Psychological effects of aerobic fitness training. New York, NY: Springer-Verlag Publishing. 
McDonald, K., \& Thompson, J. K. (1992). Eating disturbance, body image dissatisfaction, and reasons for exercising: gender differences and correlational findings. International Journal of Eating Disorders, 11, 289-292.

Miller, C. T., \& Downey, K. T. (1999). A meta-analysis of heavyweight and self-esteem. Personality and Social Psychology Review, 31, 68-84.

Nauta, H., Hospers, H., \& Jansen, A. (2001). One-year follow-up effects of two obesity treatments on psychological well-being and weight. British Journal of Health Psychology, 6, 271-284.

Nir, Z., \& Neumann, L. (1995). Relationship among self-esteem, internal-external locus of control, and weight change after participation in a weight reduction program. Journal of Clinical Psychology, 51, 482-490.

Palmer, L. K. (1995). Effects of a walking program on attributional style, depression, and self-esteem in women. Perceptual and Motor Skills, 81, 891-898.

Pasman, L., \& Thompson, J. K. (1988). Body image and eating disturbance in obligatory runners, obligatory weightlifters, and sedentary individuals. International Journal of Eating Disorders, 7, 759-769.

Perry, A. C., Rosenblatt, E. S., Kempner, L., Feldman, B. B., Paolercio, M. A., \& Van Bemden, A. L. (2002). The effects of an exercise physiology program on physical fitness variables, body satisfaction, and physiology knowledge. Journal of Strength and Conditioning Research, 16, 219-226.

Polivy, J., Heatherton, T. F., \& Herman, C. P. (1988). Self-Esteem, restraint, and eating behavior. Journal of Abnormal Psychology, 97, 354-356.

Polivy, J., \& Herman, C. P. (1992). Undieting : A program to help people stop dieting. 
International Journal of Eating Disorders, 11, 261-268.

Raglin, J. J. (1990). Exercise and mental health. Beneficial and detrimental effects. Sports Medicine, 9, 323-329.

Ramirez, E. M., \& Rosen, J. C. (2001). A comparison of weight control and weight control plus body image therapy for obese men and women. Journal of Consulting and Clinical Psychology, 69, 440-446.

Rodin, J., Silberstein, L. R., \& Striegel-Moore, R. H. (1985). Women and weight: A normative discontent. In T. B. Sonderegger (Ed.), Nebraska symposium on motivation: Vol. 32. Psychology and gender. Lincoln, NE: University of Nebraska.

Rosen, J. C., Orosan, P., \& Reiter, J. (1995). Cognitive behavior therapy for negative body image in obese women. Behavior Therapy, 26, 25-42.

Russell, W. D., \& Cox, R. H. (2003). Social physique anxiety, body dissatisfaction, and self-esteem in college females of differing exercise frequency, perceived weight discrepancy, and race. Journal of Sport Behavior, 26, 297-318.

Sands, R., Tricker, J., Sherman, C., Armatas, C., \& Maschette, W. (1996). Disordered eating patterns, body image, self-esteem, and physical activity in preadolescent school children. The International Journal of Eating Disorders 21, 159-166.

Sarlio-Lanteenkorva, S. (2000). "The battle is not over after weight loss": Stories of successful weight loss maintenance. Health: An Interdisciplinary Journal for the Social Study of Health, Illness \& Medicine, 4, 73-89.

Shiner, B., Whitley, R., Van Citters, A., Pratt, S., \& Bartels, S. (2008). Learning what matters for patients: Qualitative evaluation of a health promotion program for those with serious mental illness. Health Promotion International, 23, 275-282. 
Sonstroem, R. J., Harlow, L. L., Gemma, L. M., \& Osborne, S. (1991). Test of structural relationships within a proposed exercise and self-esteem model. Journal of Personality Assessment, 56, 348-364.

Sonstroem, R. J., Harlow, L. L., \& Josephs, L. (1994). Exercise and self-esteem: Validity of model expansion and exercise associations. Journal of Sport \& Exercise Psychology, $16,29-42$.

Sonstroem, R. J., \& Morgan, W. P. (1989). Exercise and self-esteem: rationale and model. Medicine and Science in Sports and Exercise, 21, 329-337.

Spence, J. C., McGannon, K. R., \& Poon, P. (2005). The effect of exercise on global selfesteem: A quantitative review. Journal of Sport \& Exercise Psychology, 27, 311-334.

Stice, E., Cameron, R. P., Hayward, C., Taylor C. B., \& Killen, J. D. (1999). Naturalistic weight-reduction efforts prospectively predict growth in relative weight and onset of obesity among female adolescents. Journal of Consulting and Clinical Psychology, 67, 967-974.

Teixeira, P. J., Going, S. B., Houtkooper, L. B., Cussler, E. C., Martin, C. J., Metcalfe, L. L., et al. (2002). Weight loss readiness in middle-aged women: Psychosocial predictors of success for behavioral weight reduction. Journal of Behavioral Medicine, 25, 499-523.

Tiggemann, M., \& Williamson, S. (2000). The effect of exercise on body satisfaction and self-esteem as a function of gender and age. Sex Roles, 43, 119-127.

Tremblay, M. S., Inman, J. S., \& Willms, J. D. (2000). The relationship between physical activity, self-esteem, and academic achievement in 12-year-old children. Pediatric Exercise Science, 12, 312-323.

Trujillo, C. M. (1983). The effect of weight training and running exercise intervention 
programs on the self-esteem of college women. International Journal of Sport Psychology, 14, 162-173.

Tucker, L. A., \& Mortell, R. (1993). Comparison of the effects of walking and weight training programs on body image in middle-aged women: An experimental study. American Journal of Health Promotion, 8, 34-42.

van Gemert, W. G., Severeijns, R. M., Greve1, J. W., Groenman, N., \& Soeters, P. B. (1998). Psychological functioning of morbidly obese patients after surgical treatment. International Journal of Obesity, 22, 393-398

Williams, P. A., \& Cash, T. F. (2001). Effects of a circuit weight training program on the body images of college students. The International Journal of Eating Disorders, 30, 7582. 